
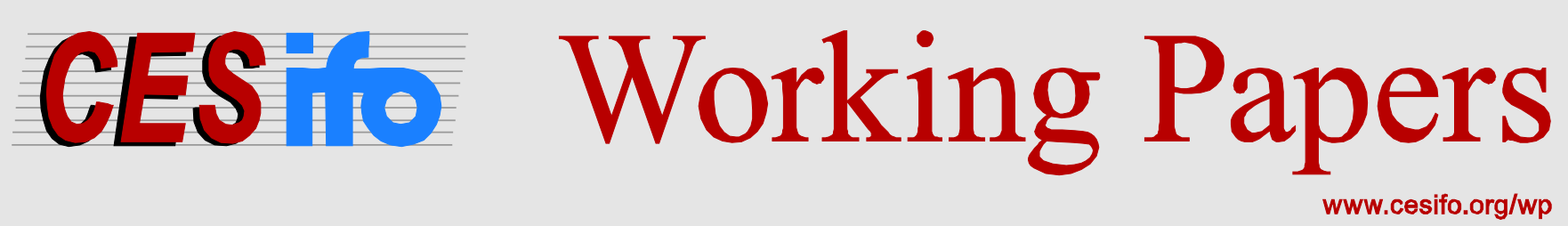

\title{
Urbanization and Growth: Why Did the Splendor of the Italian Cities in the Sixteenth Century not Lead to Transition?
}

\author{
Bruno Chiarini \\ Elisabetta Marzano
}

\author{
CESIFO WORKING PAPER NO. 5038 \\ CATEGORY 6: Fiscal POLICY, MACROECONOMICS AND GROWTH \\ OCTOBER 2014
}
An electronic version of the paper may be downloaded
- from the SSRN website: Www.SSRN.com
- from the RePEc website: Www.RePEc.org
- from the CESifo website: www.CESifo-group.org/wp

\section{CESifo}




\title{
Urbanization and Growth: Why Did the Splendor of the Italian Cities in the Sixteenth Century not Lead to Transition?
}

\begin{abstract}
In this paper we investigate the relation between population, wages and urban population in the Italian economy. During the period examined, 1320-1870, the prevailing conditions were those of a poor, mainly agricultural economy with limited human capital and rudimentary technology. However, these centuries witnessed the considerable growth of urban centers, a significant demographic phenomenon with major economic consequences. Against this background we set up a theoretical scheme to explain why urbanization did not drive the economy to sustained growth. Our main contribution, validated by an estimated VAR model, suggests that in an early stage of development, migration to cities may have negative consequences for rural marginal productivity. The analysis provides a picture of a trapped economy where urbanization was unable to trigger a persistent process of development without the support of a substantial increase in population.
\end{abstract}

JEL-Code: N330, N530, N930, J110, C320.

Keywords: urbanization, Malthusian dynamics, pre-industrial labor productivity, population trend, demographic changes, agricultural wages.

\author{
Bruno Chiarini \\ Department of Economics \\ University of Naples "Parthenope" \\ Via Generale Parisi 13 \\ Italy-80133 Naples \\ chiarini@uniparthenope.it
}

\author{
Elisabetta Marzano \\ Department of Economics \\ University of Naples "Parthenope" \\ Via Generale Parisi 13 \\ Italy - 80133 Naples \\ elisabetta.marzano@uniparthenope.it
}




\section{Introduction}

Urbanization, according to Bencivenga and Smith (1997), is a prominent aspect of economic development typically omitted from conventional neoclassical growth model. Ancient and modern economic development has invariably been accompanied by pronounced migration of the labour force from rural to urban sectors. Over the last two centuries, all the countries that have experienced the transition from traditional agricultural economies to market economies have persistently increased urbanization, reduced fertility and increased the growth rate of per capita output in market sectors. $^{1}$

The rise of the urban population in Europe indicates the extent to which specialization, associated with the division of labor, accompanied economic development. Per capita product rises as production shifts from primitive (or household economy) processes to market-based specialization techniques and the pace of this process reflects rapid urbanization. Moreover, key functions for economic development, such as banking, notary and legal activity, business and commerce, were necessarily carried out and developed in cities and grew with urbanization.

Urbanization figures show that some European countries, which were the first to abandon primitive or rural technology, became rapidly urbanized between the $15^{\text {th }}$ and $17^{\text {th }}$ century. The three countries which played a decisive role in the European economy each gained dominance in sequence and in parallel to the process of urbanization: (central-northern) Italy, the Netherlands and England. ${ }^{2}$ This issue is particularly interesting for Italy whose towns and cities already in the early Middle Ages represented splendid cultural, economic and financial centers, although a decline in urbanization began in the early 16th century. This naturally begs the question as to why the

\footnotetext{
${ }^{1}$ See, amongst others, the classical Bairoch $(1981 ; 1988)$ and Wrigley 1969, and amongst the new literature, Goodfriend and McDermott (1995), Zhang (2002), and Sato and Yamamoto (2005).

${ }^{2}$ See Malanima (2002), especially data reported in Figure 2.17 p. 91. Of course there are other factors (changes in education, property rights, preferences across social classes, culture and so on) that have impacted on economic outcomes in a country undergoing transition from stagnation to growth. See, for instance, the survey by Doepke (2006). The view that the transition from a traditionalist and religious-minded society to the individualistic and mobile world of the market society originated and developed in towns, has been credited to many authors. See, amongst others, Hicks (1969), Hohenberg and Hollen Lees (1985), Blockmans (1989) and Tilly (1990). Moreover, in some cases, the boom in urbanization could also be associated to that of the great building booms. A considerable labor supply which flooded the towns and cities allowed ecclesiastical and military architecture to flourish.
} 
development of the Italian cities in the sixteenth century did not lead to transition to sustained growth. We tackle this question in three steps. First, using univariate analysis, we investigate the economic mechanisms governing the relationship between demographic dynamics (population and urbanization) and productivity. This aspect is important since the relatively slow pace of technological innovation may be one of the conditions delaying economic transition toward sustained growth. The same aspect is stressed by the unified growth theory to which this paper belongs. Second, given the empirical evidence, we set up a theoretical scheme to show how the gap in labor productivity in urban and rural technologies may lead to stable and unstable urbanization equilibria. Third, using cointegration analysis, we assess the hypotheses underlying the above framework, estimating a VAR cointegrated model in three endogenous variables: population, rural wage, urbanization. ${ }^{3}$

Of course, some qualifications should be made. In this context, it is important to be sufficiently precise about the main events and historical facts, and it is naïve to suggest that the empirically investigated relationships may be affected by a myriad of other factors. ${ }^{4}$ Moreover, we are aware that the observable data (wages, population, output, urbanization rate) in the form of time series have undergone insurmountable difficulties. Nevertheless, these time series are the only possible candidates for measuring these variables and providing some aggregate results.

Among the main results of the paper, we find that in early stages of development, urbanization alone is not able to trigger a process of transition to sustained growth without the support of a substantial increase in population. Our analysis shows that the barrier to the transition is due to the interplay of several phenomena such as negative shocks of the population that have raged

\footnotetext{
${ }^{3}$ Although data pose unavoidably serious problems, there is a large and growing body of literature which studies economic and demographic relations in pre-industrial Europe. See Weir (1991), Lee (1997), Lee and Anderson (2002), Malanima (2005), Clark (2006), and Crafts and Mills (2007). Eckstein et al. (1986), Bergtsson and Brostrom (1997), Nicolini (2006) and Chiarini (2010), amongst others, use VAR analysis to investigate demographic and economic relationships.

${ }^{4}$ Obviously a caveat is called for. The history of the Italian economy is orders of magnitude more complicated and dramatic than this simple time series description. Many features of the history of growth are omitted. Of undeniable importance are the evolution of physical and human capital, property rights, new ideas and institutions, and religious constraints to their diffusion, foreign dominance, and many other factors and events. Here we quote the papers in Storia d'Italia (1974) and Luzzatto (1961).
} 
repeatedly over the period considered; insufficient growth of rural technology, necessary to support urbanization; migration (of the young and educated workforce) to urban centers that has repeatedly depleted agriculture.

The paper is organized as follows. Section 2 describes the urbanization process in Italy during the pre-industrial epoch, comparing the evidence from Italy and other parts of Europe. Section 3 describes the data set and analyses the dynamics of the demographic variables (i.e. population and urbanization) as well as economic variables (real wages in agriculture and the share of agriculture in total GDP). Section 4 discusses the technology-population relationship and the implications of the urbanization process, using Italian data. Section 5 sets up the conditions and assumptions of a theoretical framework suitable to describe the missed transition in Italy in the 16th century. Section 6 reports the simulations obtained using our VAR model. Section 7 summarizes the results and implications, while some Appendices show the statistical characteristics of the available time series and a detailed analysis of the model estimates.

\section{A brief history of urbanization in Europe and Italy in the pre-industrial era}

At the time when the Italian population peaked (between the 1290s and the 1340s), urbanization in Italy had reached much higher levels than elsewhere in Europe, although it was not evenly distributed country-wide. In the rest of Europe there were no more than eight cities with over 40,000 inhabitants (Paris, London, Cologne, Barcelona, Ghent, Tournai, Rouen and Montpellier) and their sizes were considered exceptional. In Italy there were 11 cities with populations exceeding 40,000, four of which even exceeded 100,000 inhabitants.

The extreme importance of the Italian urban network may be fully appreciated if one considers that there were 13 towns larger than 20,000 inhabitants and 59 well above 10,000. Also, during this 
period, there were over 100 towns with a population between 5,000 and 10,000 inhabitants. Such urban concentrations would be termed medium-sized towns at the European level. ${ }^{5}$

Hence, in Italy in the period in question the urbanization process was far greater than in Europe.

This was not only due to the larger towns involved but also a lively connective network comprising 59 urban centers with 10,000-20,000 inhabitants and 67 towns with about 10,000. Regional differences were quite evident, with major towns concentrated in northern areas and in Tuscany. Keeping the threshold of 10,000 inhabitants, the urbanization rate was 18 percent in Italy -as in Flanders -- while the European average was 5.3 (Malanima 2009).

After the first few decades of the 14th century, however, a dramatic demographic transformation began, with repeated severe mortality crises, starting with the Black Death affecting Italy in 134749, which caused a general reduction in urban populations. Lucca, Pistoia, Verona, Padova, Treviso, Como, Pavia, L'Aquila and Sulmona lost half their populations, while most of Tuscany suffered an extreme decline in urban populations; Arezzo and Prato lost three-quarters of their inhabitants, while Pisa, Massa and many other cities came to lose four-fifths of the population. The cities of Emilia Romagna, Piedmont and Sicily lost less, but for many of them about half the population died. Very considerable losses also occurred in the Kingdom of Naples and the Papal States. Many small and medium-sized towns in Central and Southern Italy disappeared. When the Black Death appeared (1348-49), in Italy the population was 12-13 million; the plague killed 3.5 million (about $27-30 \%$ of the population). ${ }^{6}$ In the next phase, there clearly emerged a lower resilience of the urbanization process with overall downsizing of the urban system, in particular in some regions (Tuscany, Central and Southern regions). However, this process was not uniform: while Florence

\footnotetext{
${ }^{5}$ On the history of medieval Italian cities and the urbanization process, there is a huge bibliography, carefully proposed and adequately supported by data and documents in Ginatempo and Sandri (1990) and Pini (1996). Data on European cities are taken from these authors from works of L. Genicot, H. Amman, C. Haase, J. Le Goff, C. Dury, E. Ennen and several others. The data are carefully documented and compared.

${ }^{6}$ Malanima (2002) reports a fascinating and dramatic reconstruction of the evolution of the plague and the fatal diseases of the age. Among the vast literature we cite the data reconstructed by Del Panta (1980) and Bellettini (1973). Even more dramatic data on the disastrous waves of plague are reported in Alfani and Melegaro (2011) and Alfani (2013a). See Helleiner (1967) , Ziegler (1969), McNeil (1977) for an analysis of the plague in Europe.
} 
and Rome were experiencing a wonderful renaissance, the cities of Sicily and the Po valley showed a lively revival between 15th and 16th centuries.

In 1560 no more than five European cities had reached a population of 100,000. Except for Paris, the others were Italian (Naples, Genoa, Venice and Milan). Other large cities were Bologna, Verona, Palermo, Rome and Messina. They created favorable conditions for new epidemic outbreaks. The concentration and the "mushrooming growth" of large and small towns seems to have stopped after the Italian epidemic of 1656-57 (see, for instance, Lopez and Miskimin 1962, and the papers in Miskimin et al. 1977)

During the subsequent period Italy experienced great dynamism in its rural population alongside urban stagnation: an unusual development on the European scene, where the percentage of towndwellers was slowly rising. Around 1870, while the European urbanization rate had grown to 15.2 (cities with at least 10,000 inhabitants), the Italian rate had fallen to 13.3. At that time European cities numbered 1,299. In the centre and north of Italy they were 66. From being the most urbanized region of Europe during the Renaissance, this part of Italy was then among the least urbanized (see amongst others, De Vries, 1984, and Bosker et al., 2008).

\section{Population, wages and urbanization in pre-industrial Italy}

\subsection{The data set}

Our empirical evidence is based on time series provided by Malanima (2002; 2003; 2005), where data are reconstructed for population, nominal and real rural wage rates, GDP and per capita GDP (total and agriculture), prices of agriculture goods and urban population density. Output variables, rural wages, population and urbanization rates are measured for central-northern Italy. ${ }^{7}$ Measurement of urbanization used in the models below is the proportion of the population in towns

\footnotetext{
${ }^{7}$ Specifically, Piedmont (with Val d'Aosta), Lombardy, Veneto, Trentino Alto Adige, Friuli, Istria, Liguria, EmiliaRomagna, Tuscany, Umbria and Marche.
} 
of 5,000 or more inhabitants. ${ }^{8}$ All the monetary variables are indices with base in the decade 1860 70 (the last observation of our sample).

As regards notation, $W$ represents wages in the agriculture sector. To obtain the real aggregate we used the price index for agricultural goods $P$. When referring to wages, we mean real wages in the primary sector. With regard to output, $Y$ stands for GDP, and $Y a$ for the agricultural product. Hence the share of agricultural to total GDP, $A g r \_$share, is represented as $Y a / Y$. Demographic variables are Pop for population, and Urban for urbanization rates in central-northern Italy. Since the original variable Urban alternates phases of stability with sudden jumps (the pattern is characterized by several steps), which create difficulties in statistical analysis, we use as a proxy for urbanization its long-run trend estimated through the HP filter.

The data series are in decadal frequencies; our sample covers the period going from the decade $1310 / 20$ up to 1860/70. The data in ten-year intervals present two problems. First we cannot study short-term interaction but the results will reflect longer term tendencies. Second, the sample size (55 observations) is not large enough to render analysis of subsamples possible. Statistical series on these variables might be thought to lack reliability. Direct and official estimates are available for Italy as well as many other countries from the mid-19th century onward (see McEvedy and Jones 1978; De Vries, 1984). As far as we know, the reconstruction of these data was accurate and broadly accepted by historians who analyze the period, as recently stressed by Broadberry (2013) with regard to the short-cut method for reconstructing GDP used by Malanima and several other authors for different countries in Europe. The detailed analysis of the reconstruction is shown in Malanima (2002). It is obvious that such a long and necessarily complex reconstruction of the period may give rise to doubts in both methods in the assumptions used to obtain the data. For instance, the population of central-northern Italy was partially reconstructed through the aggregate method of inverse projection, using, for a period, the demographic movement in Tuscany and the reconstruction of Karl Julius Beloch. The problem here is the motivation of these assumption and

\footnotetext{
${ }^{8}$ See Malanima (2002; 2005) for detailed analysis and a reconstruction of urbanization rates in Italy.
} 
their generalization. Certainly our conclusions, like those of any studies that are not based on data reconstructed from official sources, may be the consequence of shortcomings of the database, which is why they have to be viewed with caution. However, the analysis of data construction seems accurate, well-documented and rich in detail with many verifiable assumptions. Moreover, statistical series may be compared with other studies and estimates (see Malanima 2002, 2013). That said, it constitutes the best available data set for the period.

\subsection{The stylized facts}

The dynamic of population, urbanization rate, agricultural GDP, rural wages/productivity and rural prices in Italy during the 14th-19th centuries are shown below in Figures 1-5. The patterns of population and urban communities across the period are reported in Figure 1. In the early decades of the 1500s, the trend of the two demographic variables began to differentiate, with a progressive growth in population and a decline in urbanization.

Figure 1: population (thousands) and urbanization rate (HP trend), 1320-1870

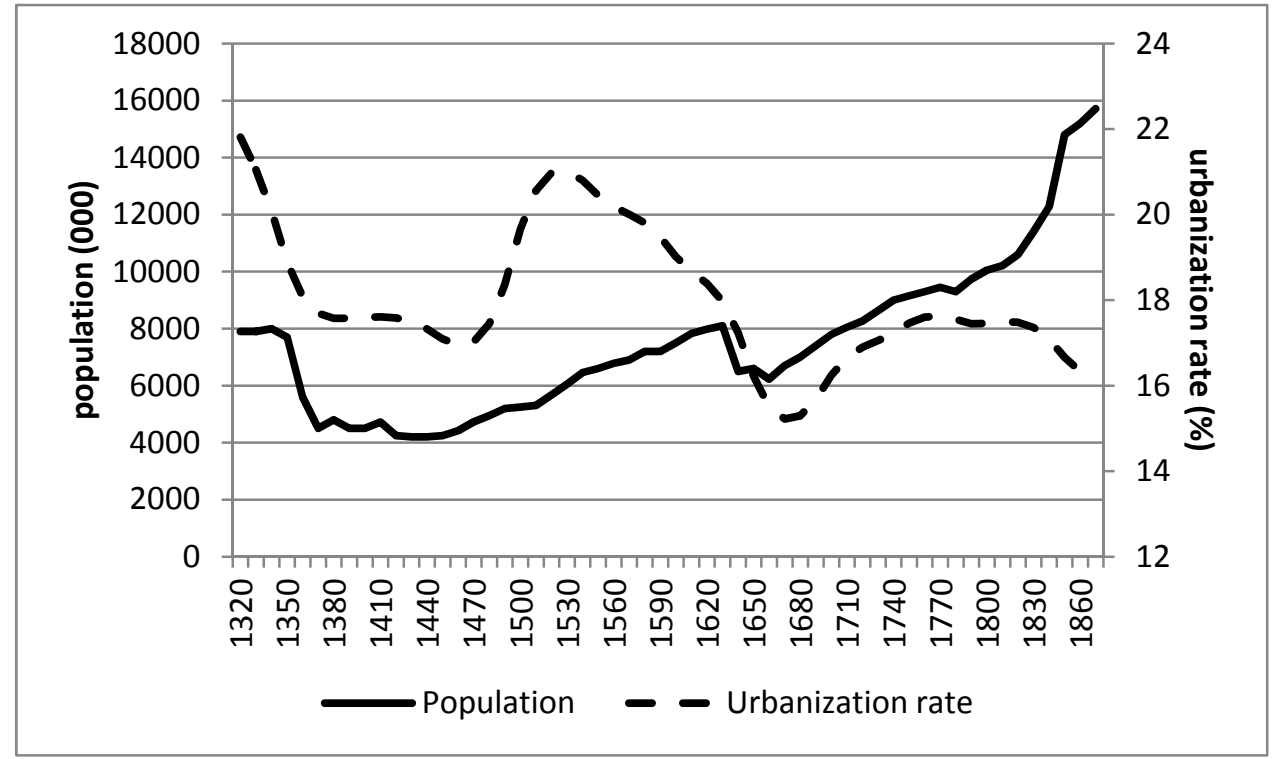


The dynamic path followed by population (Centre-North Italy) shows that after the outbreak of the Black Death in 1347-48, the population regained its level of about 8 million only in the decade 1620-30. A new plague pandemic (1629-30 in northern Italy) caused another demographic decline, followed by a recovery that finally allowed the population to grow beyond what Alfani (2013a,b) defines its millenary limit. As for the urbanization rate, a declining trend is observed throughout the sample, with a maximum peak recorded in 1530 (21\%) and a minimum in 1670 (15\%). As we will see, these dynamics played a crucial role in the Italian economy because of the complex interactions between population, productivity and urbanization. The latter plays a crucial role in economic transition, as is intuitive from Figure 2, where we plot the urbanization trend and the ratio of agricultural to total GDP.

Figure 2: share of agricultural GDP and the urbanization rate (HP trend), 1320-1870

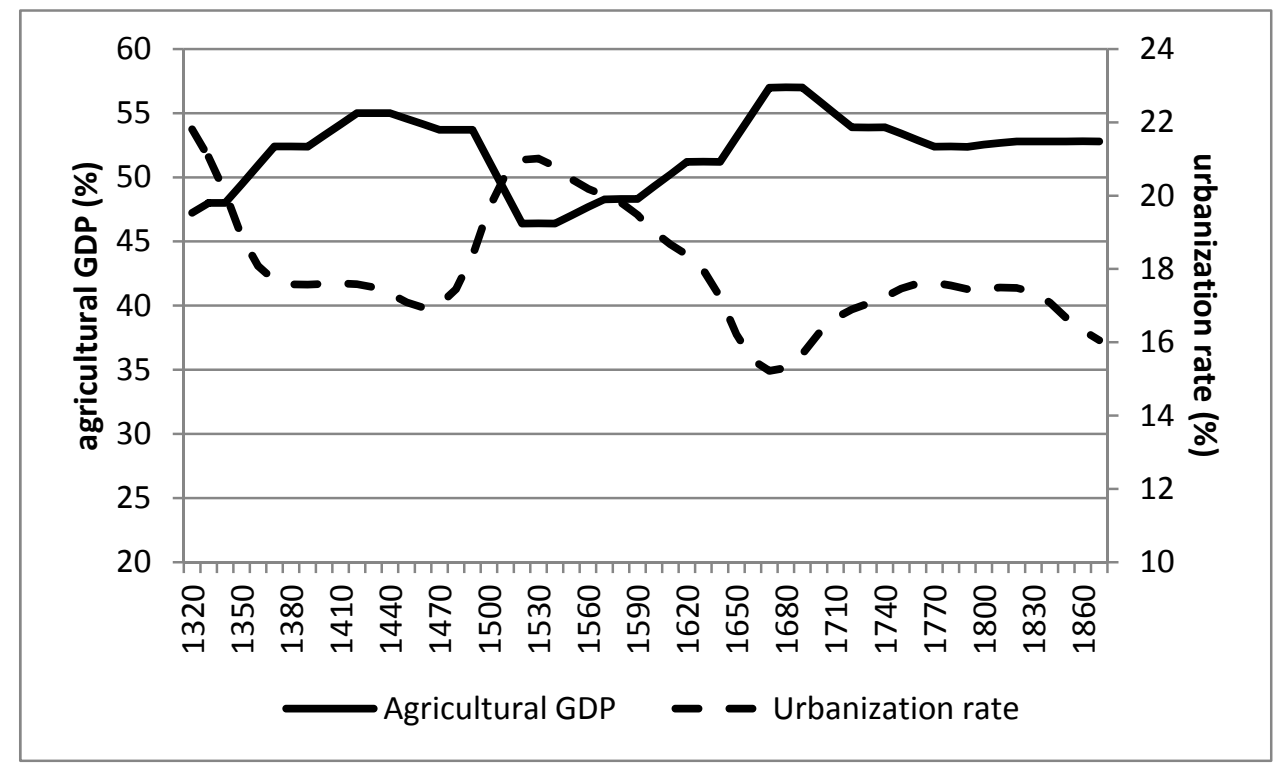

The existence of a negative co-movement between the two variables is evident, and we find that the turning points of the urbanization rate and agricultural share are almost perfectly synchronized. Hence it might be inferred that a larger proportion of urban inhabitants facilitates rising value added in "industry" and services, mostly located in cities, contributing to reduce the weight of agricultural to total GDP. Indeed, an appropriate test of Granger causality, performed in a VEC framework due 
to the non-stationary characteristics of the variables (see the Appendix), indicates two-way causation. $^{9}$

We now turn to the relationship between population and wages which is, in the presence of decreasing returns to scale and for a given level of technology, undoubtedly negative. Figure 3 shows that real wages in the agricultural sector (indexed to 1 in 1870) experienced an extraordinary decline during the observed sample, from a maximum peak of 27 in 1320 to a minimum of 0.72 recorded six centuries later. As Figure 3 clearly shows, factors that reduce population lead to high agriculture labor productivity (and wages). For instance, after the Great Plague of 1347-48, wage gains in agriculture were large; wages remained high until the mid-15th century when rapid population growth reversed the wage trend.

Figure 3: real wage in agriculture (1870 indexed to 1$)$ and population (thousands), 1320-1870

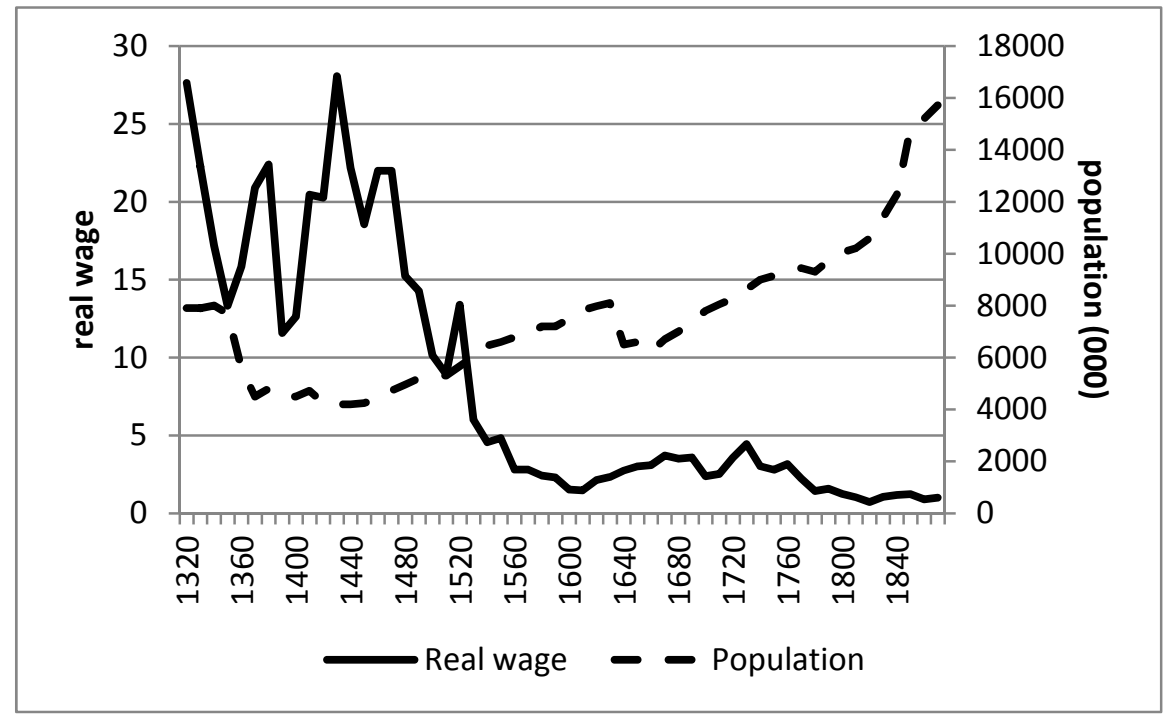

The post-plague decades show a significant upward movement in population, reducing the efficiency of the rural economy and bringing down wages in agriculture. The so-called "horsemen effect” (rise in war frequency, deadly disease outbreaks and urbanization) which, in general, pushed up mortality rates and produced higher per capita income, was unable to render permanent the rise

\footnotetext{
${ }^{9}$ The null hypothesis that each variable is not Granger causal for the other is rejected at the 99\% confidence level.
} 
in productivity and rural wages subsequent to the Black Death. ${ }^{10}$ Contrary to what happened in most of Europe, in Italy there was a considerable wage decline after $1500 .^{11}$

Turning back to the sudden growth of urbanization rates in the second half of the fifteenth and sixteenth century, a natural question arises: why did economic transition not happen? A possible explanation relies on the evidence displayed in Figure 4, where we plot real wages and urbanization against time, showing a period of high urbanization and rural productivity decline. The low productivity in rural areas surrounding cities and towns may well have constrained urban expansion, which indeed also declined some decades after the productivity slow-down,.

Figure 4: real wage in agriculture (1870 indexed to 1) and urbanization rate (HP trend), 1320-1870

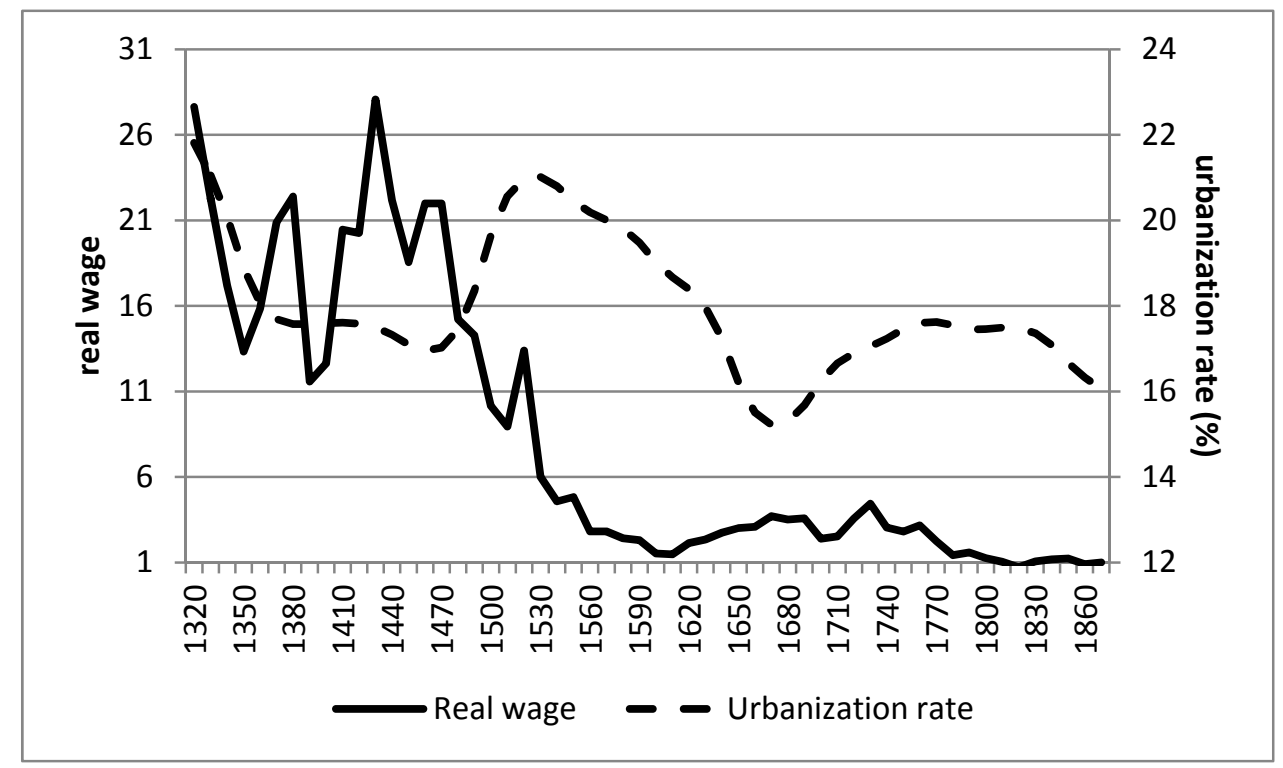

Interestingly, the decline in urbanization starting in the early 16th century followed a downward shift in rural productivity and a jump in rural prices (see Figure 5), whereas a new phase of

\footnotetext{
${ }^{10}$ Voigtlander and Voth (2013) state that war and trade-related mortality shifted the death schedule upward and, together with the effect of urbanization, this created a new mortality regime, reducing population pressure and making the initial income gains after the Black Death sustainable. Trade, war and urban centres, "the horsemen”, pushed up the mortality rate, spreading plague, typhus, smallpox and other disease across Europe.

${ }^{11}$ Italy had higher per capita GDP in the 1300s than in 1700-1800. On wage dynamics in the pre-industrial era in European countries see, amongst others, Allen (2001), Acemoglu et al. (2005), Malanima (2003) and Voigtlander and Voth (2013).
} 
urbanization during the period 1670-1800 was preceded by a recovery in agricultural wages and followed by a resurgence of prices.

The increase in the prices of agricultural products is an inevitable result in a context of declining productivity and high urban demand: with an increasing urban population, and in the presence of a reduction in agricultural products and foodstuffs, the prices of the latter necessarily rise. Figure 5 provides further insights into the links between per capita agricultural product and prices in the rural sector throughout the period examined. We observe the decline of productivity in the period 13201570 along with a rise in agricultural prices, with the exception of the arrival and spread of the plague, which spurred agricultural productivity. From the second half of the sixteenth century until the end of the period examined, the two variables appear to be almost perfectly negatively correlated. This evidence, along with the pattern of urbanization, suggests that migration to the cities was not sustainable with the existing technology.

Figure 5: Prices and productivity in the rural sector

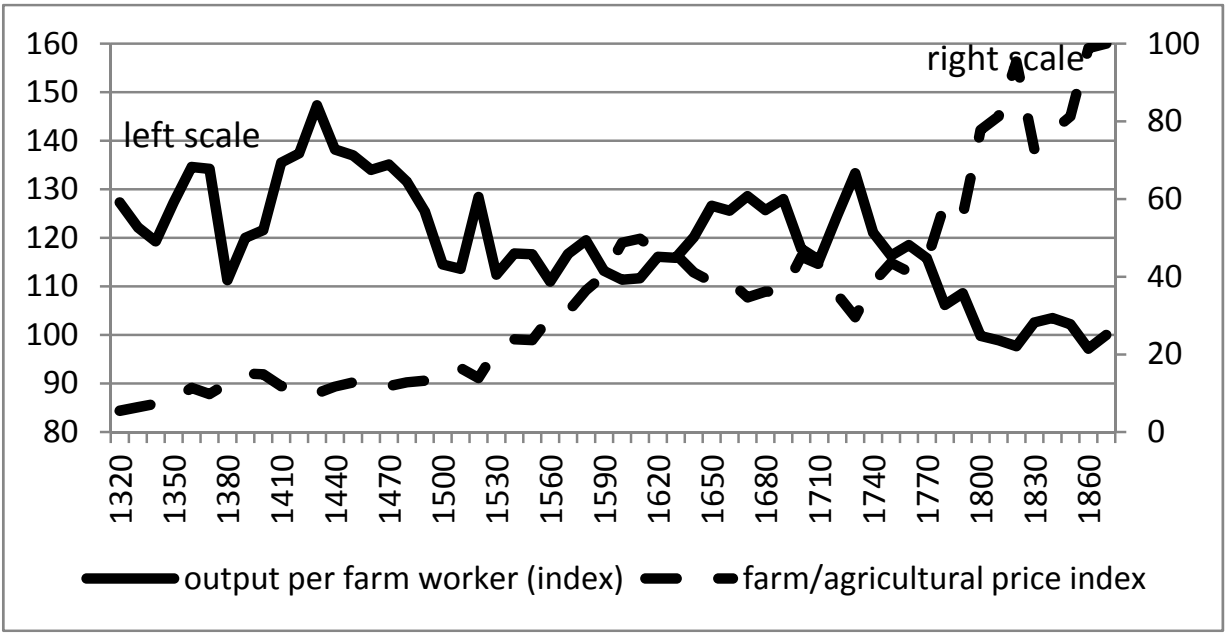

This first inspection of the data depicts a scenario which may be used to answer our main question. First, urbanization seems to be able to play a role in economic transition, by reducing the agricultural share of GDP. Second, high urbanization can coexists with low agricultural productivity 
although only high productivity can sustain a higher proportion of the population living in cities. This complex interaction will be better investigated in Sections 5 and 6 . As we have seen, Italy had a dense network of urban centers in medieval times, but productivity had already started to decline by the mid-15th century, perhaps contributing to reduce the network of towns into empty urban nuclei by $1700 .{ }^{12}$ Such declines in rural wages and urbanization occurred when the leading cities in northwest Europe experienced higher urbanization rates and maintained higher levels of real wages. For instance, although rural wages showed a substantial drop in the England countryside in the 16th century, they rebounded in the next century. ${ }^{13}$

\section{Technological progress and population}

The preliminary evidence shown in the previous section suggests that rural productivity has been crucial in delaying the transition despite the evolution of towns and cities since the fourteenth century. However, the relationship between urbanization and rural productivity is much more complex than the evidence so far depicted. Indeed, a possible side-effect of urbanization is to empty the countryside of the younger and more efficient workforce, contributing to reducing, in the absence of technological progress, agricultural productivity. In the next section we sketch a theoretical scheme to support this hypothesis. Here we focus on the Boserupian mechanism, namely, how population size triggers technological progress in the early stages of development. It is well known that technology plays a crucial role in models of economic growth, and the unified growth theory (Galor, 2005) suggests that the positive feedback from population growth to technological progress is the key mechanism that brought the Malthusian phase to an end. The transition from the Malthusian epoch to economic development was triggered when the rate of

\footnotetext{
${ }^{12}$ See De Vries (1984) and the data on European urbanization based on Bairoch, Batou and Chevré and reported by Voigtlander and Voth (2013).

${ }^{13}$ See, amongst others, Clark (2007) who outlines the relationship between higher real wages and rapid urbanization which, under negative shocks, required a higher equilibrium real wage to balance births and deaths in England and the Netherlands during the transition epoch. Of interest is also the critique of Allen (2008) who stresses that the "difference in urbanization cannot explain the wage divergence between the winners and the losers in the early modern economy.”
} 
technological progress overtook the rate of population growth, hence allowing GDP per capita to increase.

In a seminal paper, Kremer (1993) models the interaction between population and technological change during the Malthusian epoch, starting from the view that a larger population means a potentially larger number of inventors:

$$
\dot{A}=(A)(g)(p o p)
$$

Equation (1) indicates that technological progress is achieved through a production function using the current level of total factor productivity $(A)$, the labor input, population (pop), and per capita research productivity, $(g)$. The latter, in the basic formulation, is exogenous, although it can also be considered as a function of income, technology and/or population. For instance, by generalizing the “research technology" equation (1) to allow the current level of technology to have a non-linear effect of technological progress, we may obtain a relationship between technology and population which is also consistent with the productivity slow-down experienced during recent decades:

$$
\dot{A}=(A)^{\emptyset}(g)(p o p) \quad \emptyset<1
$$

Although the variable $g$ is not directly observable, following Kremer (1993), it can be derived in the basic formulation of Equation (1) from the proportional relationship between the growth rate of population and its level:

$$
\frac{p \dot{o} p}{p o p}=\frac{g}{1-\alpha}(p o p)
$$

where $(1-\alpha)$ is the elasticity of land in the (Cobb-Douglas) output production function. ${ }^{14}$ Alternatively, with reference to the more general formulation of research technology, the population growth equation reads as follows:

$$
\frac{p \dot{o p}}{p o p}=\frac{g}{1-\alpha}(p o p)^{\emptyset} A^{\emptyset-1}
$$

\footnotetext{
${ }^{14}$ Assuming constant returns to scale for labor and land in the output technology, $Y=A(p o p)^{\alpha}(\operatorname{Land})^{1-\alpha}$, the population determination equation reads as follows: $p o p=\left(\frac{y}{A}\right)^{1 /(\alpha-1)}$, where $y$ stands for per capita output. Equation (3) is derived by taking the log derivative of the population equation and substituting it into Equation (1).
} 
In both cases it is possible to derive per capita research productivity, which is directly proportional to the population growth rate. However, from Equation (4) it is clear that generalized research technology means that per capita productivity is no longer exogenous, whereas it is a function of the level of technology, $A$. By using the definition of per capita output (with land normalized to one), $y=A(p o p)^{\alpha-1}$, we can express Equation (4) as follows:

$$
\frac{p \dot{o p}}{p o p}=\frac{g}{1-\alpha}(p o p)^{1-(1-\alpha)(1-\varnothing)} y^{\emptyset-1}
$$

Equations (3) and (5) provide two different measures of the research productivity per person $(g)$ in Italy during the period 1340-1860. In the first (Equation 3) per capita research productivity is exogenous, whereas in Equation 5 it is modeled as a function of the level of technology. We plot the per capita productivities in Figure 6, whose inspection suggests two issues worth commenting upon.

Figure 6: per capita research productivity, exogenous (dashed) and as a function of technological level (solid), 1320-1870

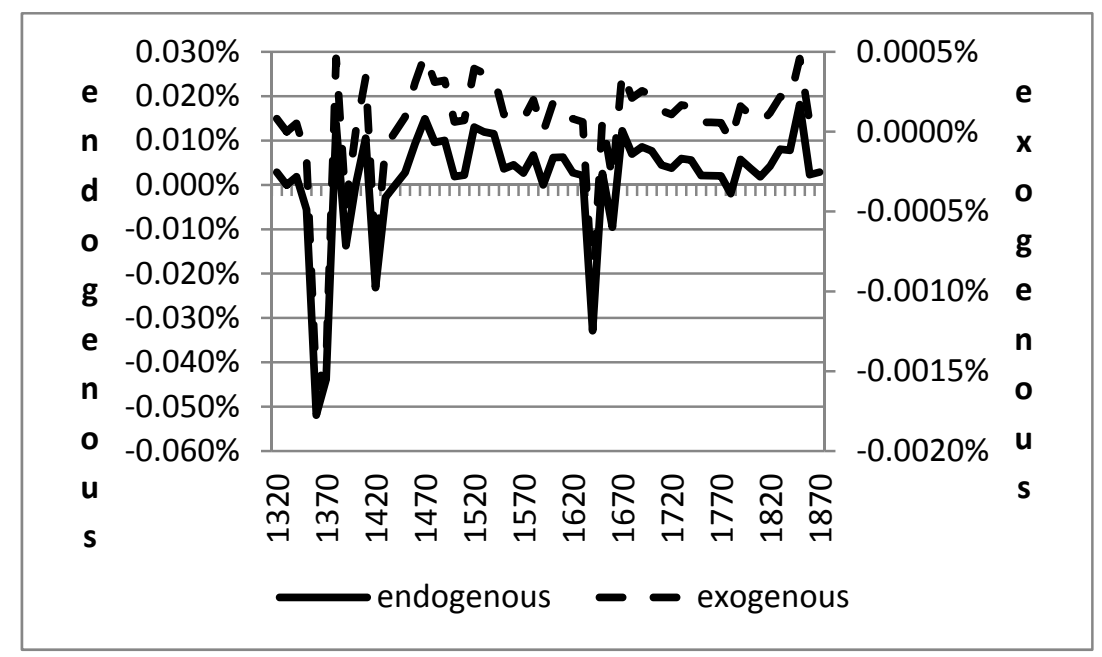

First, it is quite evident that both the calculated productivities are far from constant. For instance, with regard to the exogenous one, during the period 1460-1490 the decadal rate of technological growth (per thousand inhabitants) driven by the per capita productivity was about $0.003 \%$, with a 
maximum of about $0.005 \%$ in 1470 ; similar growth rates were reached during the period $1520-1540$ (Figure 6). ${ }^{15}$

Second, the dynamic of per capita research productivity is almost identical for the two measures: the consideration of productivity as a function of the technological level only affects the scale, whereas evolution over the sample is deeply affected by the population dynamic, as measured by its growth rate (see Figure 7).

Figure 7: population growth rate and endogenous per capita research productivity in Italy

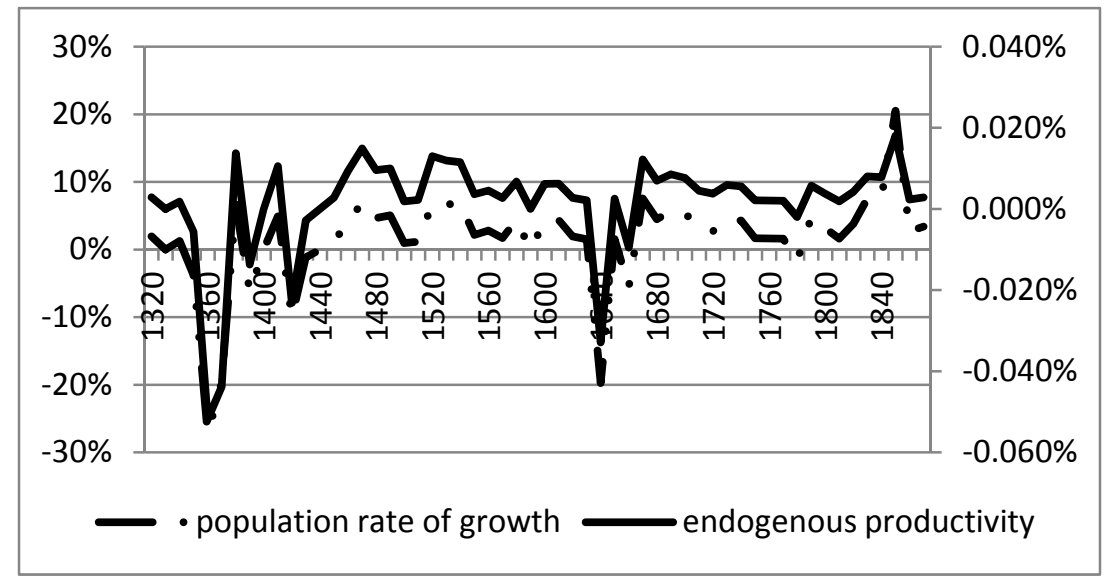

This evidence suggests two factors that may help to explain rural/urban dynamics and stagnation in Italy. First, per capita research productivity is very low during the observed sample, but deeply affected by population growth. Hence, in a two-sector economy, the urbanization process, by reducing the rural population, is also believed to have an impact on relative productivities. At first glance, urbanization, by reducing the rural population, should increase rural wages via decreasing returns to scale. However, the process of urbanization tends to depopulate the countryside, especially of a young labor force that is more prone to learning, reducing the productivity of the agricultural workforce (see Section 5).

\footnotetext{
${ }^{15}$ Although the per capita productivities are very low, it should be recalled that they contribute to GDP growth through the dynamic of the TFP stated in Equation 1 and in Equation 2. For instance, with regard to the exogenous per capita research productivity, the ten-year growth rate of TFP would be $1.38 \%$ in the decade $1450-60$ and $2.27 \%$ ten years later.
} 
Second, from Figures 6 and 7, one can derive further confirmation of the lack of technological innovation in the Italian economy over the centuries examined. The figures reported above, along with the stationarity tests reported in the Appendix, show that the population growth rate, as well as per capita productivity, are both stationary processes. ${ }^{16}$ This implies that the estimated series of the per capita research productivity is not permanently shifted by any exogenous change, such as a demographic shock. The latter, in the examined sample, is unable to trigger a process of permanent deviation from the long-run average technological progress. Although the nexus between per capita research productivity and population dynamic was very intense during the examined sample, in the Italian Malthusian era, the technological frontier remained far removed from the working environment of most individuals who lived in rural areas, and the scale of the population was unable to shift the rate of technological progress. The environment concerning the division of labor, the process of urbanization and the scale of population did not give room for supplying new ideas or generating demand for new technologies and their diffusion. Microeconomic evidence from studies on a technical level and the division of labor in the rural world confirm this hypothesis. The farmers were not using particularly advanced tools and, in addition, the form of organization of labor in agricultural was rather archaic. Malanima (2002) states, for instance, "at the end of the nineteenth century, the Italian farmers did not have much better equipment than the settlers in the High Middle Ages already used". A widespread type of plow throughout the Middle Ages was the symmetrical plow, although it was ineffective for good plowing. For several centuries improvements to agricultural implements, in general, had a relatively limited importance. Such tools and the existing labor division required labor-intensive production and did not push toward technological innovation. In a context of split estates and with increasing population pressure, farming families were forced to dramatically increase working intensity (Cafagna, 1989). Moreover, the fundus

\footnotetext{
16 In the appendix it is demonstrated that population is integrated of order 1, i.e. it is a random walk, though with a deterministic trend.
} 
(podere), was the dominant form of enterprise, where the family resided in the vicinity of the crops, and the landowner used sharecropping rather than hiring workers with specific tasks.

\section{Urbanization and economic transition}

In the pre-market period, the appearance and development of towns was a condition for industrialization and economic development. Economists and historians such as Boserup (1981), Goodfriend and McDermott (1995), Acemoglu et al. (2005) and Malanima (2009) have highlighted this aspect, which emerges eloquently from the data.

Figure8: population growth rate (average annual rate over 50 years) and urbanization rate

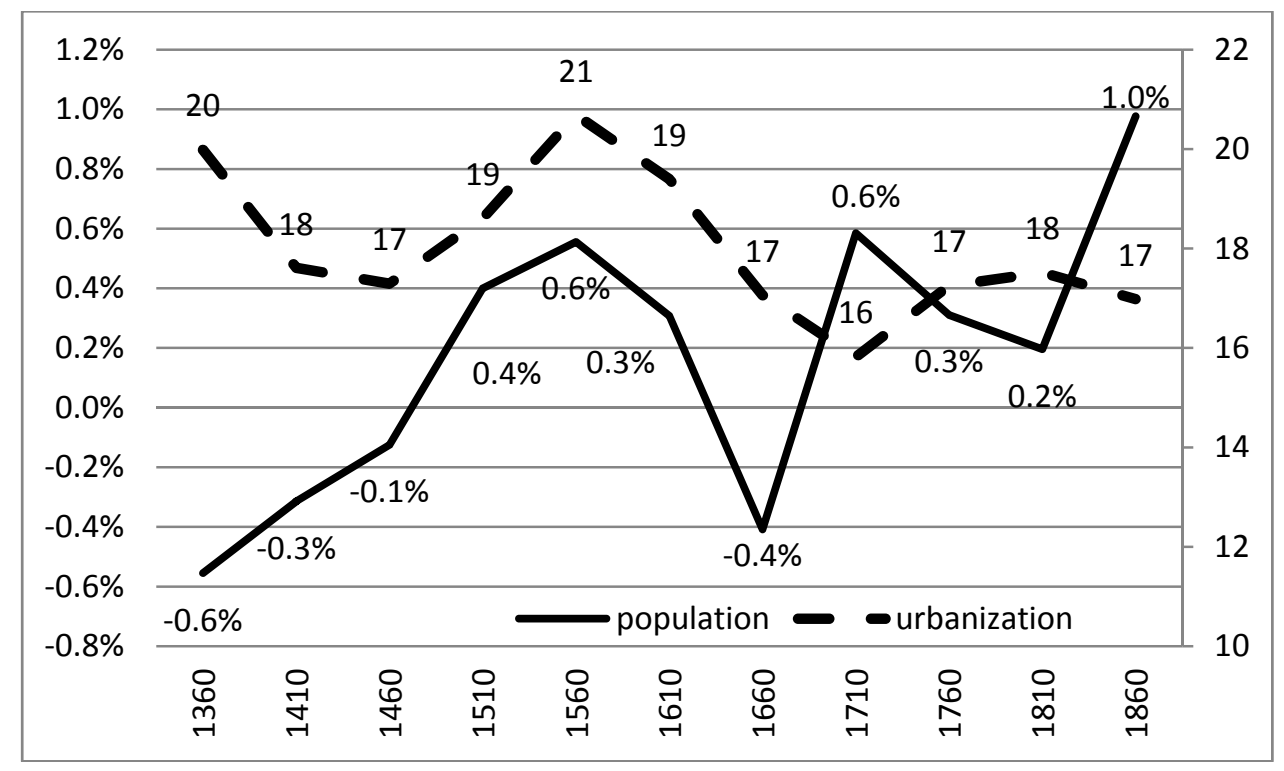

Although the literature usually assumes that the increase in urbanization runs parallel to the development of market-based production, thereby escaping from the Malthus trap thanks to increasing returns in urban/market technology, urban development in Italy in the early Middle Ages did not trigger a process of economic transition. The pre-industrial epoch continued for many decades, and the process of urbanization slowed down. Indeed, as shown by the annual rates of population growth over fifty years and urbanization in Italy (Figure 8), during the first period of strong population growth, 1460-1620, the urbanization rate peaked and stayed above 20 per cent 
throughout the 16th century. Why did the mechanisms suggested by the existing literature not work? Among the various possible causes, three of them appear attractive to the Italian case:

1. the total population was too small and growth rates were too low to develop a market large enough to start market-based technology(Goodfriend and McDermott, 1995) and to allow a process of innovation in rural technology (Boserupian innovation); ${ }^{17}$

2. cities drained resources from the countryside, reducing the already low rural productivity. Recent studies on the economics of agglomeration suggest that more skilled, younger people tend to locate to cities (Glaeser and Ressenger, 2009). We suggest that a similar dynamic was operating during the early stage of development, especially during the pre-industrial stage. Those moving to towns were skilled, younger people, and this migration generated a reduction in rural productivity, counteracting the positive effect due to decreasing returns of scale; $^{18}$

3. institutional features limiting the extent of the market, mostly related to the fragmentation of Italian States (see Epstein 2000), that were managed by different monarchies and often under the control of foreign powers in conflict amongst themselves. ${ }^{19}$

\footnotetext{
${ }^{17}$ See for instance Boserup (1965) and more recently Kremer (1993). See also Alfani (2013b) for a recent discussion on population dynamics and Boserupian innovation in pre-industrial Italy. Of course, the literature has stressed other candidates to explain the takeoff. In particular, the role of declining mortality rates, or that of increasing labor force participation and changes in the labor and education laws (Galor and Weil, 2000; Boucekkine et al., 2002; Cervellati and Sunde, 2005; Doepke, 2004, 2005; Soares, 2005; Doepke and Zilibotti, 2005).

${ }^{18}$ Cipolla (1969), amongst others, reports a series of references regarding the demands of education for some urban crafts. Literature generally recognize that the jobs in the urban sector carry education requirements that exclude individuals with no education. See Lewis (1954) and Cole and Sanders (1985). Of course, we are aware that migration, sometimes substantial, from the countryside to the cities can be related to other determinants, for instance episodes of famine.

${ }^{19}$ After the Treaty of Lodi in Italy there were many independent states, the most important of which were: the Duchy of Milan, Republic of Venice, Signoria of Florence, the Kingdom of Naples, and the Papal States. A detailed analysis of the evolutions in the Italian city in 13th-16th centuries, and the scaling process of urbanization is in Ginatempo and Sandri, 1990. The importance of a national market was pointed out by Braudel (1974) who suggest that the missed industrial development of Italy in the mid of the 15th century could be traced back to a lack of workforce or to the lack of a national market.
} 
Both points 1 and 3 are well documented in the literature and evident in the data, whereas the innovative aspect of our analysis is related to the influence of rural/urban migration on human capital and on the possible escape from the Malthusian trap.

\subsection{Urbanization and human capital: an analytical framework}

The seminal studies on migration and economic development can be traced back to the models by Lewis (1954) and Todaro (1969). Both the classical and neoclassical models of migration leave open the question of the selection process driving migration. In other words, it is assumed that the workforce is homogeneous across sectors, as well as within sectors. The new economics of labor migration, by contrast, offers new insights into the issue of migrant selectivity in terms of human capital. According to Todaro (1980), migrants: “tend to be disproportionally young, better educated ..than the general population in the region of out-migration”. Here we follow this line of research, assuming that rural technology displays, at least in a range of labor input, increasing marginal productivity. By contrast, consistent with the literature, urban technology displays increasing marginal productivity for every level of labor input. To simplify the analysis, the problem we are studying is set in a static framework, with a given population and a single homogeneous good. For the sake of simplicity, let the size of workers and population be the same. For a given endowment of labor, the share of workers engaged in rural technology is $l_{a}$ while $l_{U}$ is the relative size of the workforce employed in urban technology. ${ }^{20}$ Hence, rural and urban technology, respectively $Y_{A G R}$ and $Y_{U R B}$, can be written as follows:

$$
\begin{aligned}
& Y_{A G R}=f\left(l_{a}\right) \quad f^{\prime}>0 ; f^{\prime \prime} \lessgtr 0 \text { if } l_{a} \lessgtr \hat{l} \quad(6), \\
& Y_{U R B}=g\left(l_{U}, L_{T O T}\right) \quad g_{1}^{\prime}>0 ; g^{\prime \prime}{ }_{1}>0 ; g^{\prime}>0 ; g^{\prime \prime}{ }_{2}<0 \quad \text { (7), }
\end{aligned}
$$

\footnotetext{
${ }^{20}$ In the following we will use indifferently the term urbanization and share of urban workforce, since $\left(1-l_{a}\right)$ is the size of urban workers migrating from rural areas to cities.
} 
where, for a given level of population/workforce, $L_{T O T}$, rural productivity is increasing only if the share of rural labor, $l_{a}=L_{A G R} / L_{T O T}$, is higher than a threshold, $\hat{l}$. The hypothesis of convexity of rural technology with respect to the share of the rural workforce means that when there is migration of labor from the rural areas to towns, there is, at first, a drop in marginal productivity in rural areas. This is consistent with the assumption that those migrating first are the most skilled/young workers. ${ }^{21}$ Thus the threshold $\hat{l}$ represents a key point, since it determines, through migration, a structural change in the yield in the agricultural technology. As to urban technology, it shows increasing marginal returns to labor, and is positively related to the total population size: the larger the population the larger the market for urban-produced goods (Goodfriend and McDermott, 1995). In our graphical analysis we refer to the threshold in terms of urban employment/urbanization, namely $\hat{l}_{U}$ is the critical threshold of urbanization, above which marginal productivity of labor is positively sloped in rural technology.

We can illustrate the role of urbanization in the pre-industrial epoch in a graphical analysis. Figure 9 shows the paths and the equilibria of productivity in the two technologies (Urban and Agriculture). Curves $\Pi_{a}$ and $W_{U}$ depict, respectively, the productivity path for rural and urban labor. The vertical axis measures the productivity of the work while the horizontal axis shows the flow of migration from the rural sector to urban production (extreme right). Going from the origin of the Cartesian axes to the right, the share of agricultural labor decreases and that of urban labor increases.

According to Equation (7), for a given population, the urban sector wage monotonically rises with $\left(l_{U}\right)$, whereas the marginal product in the rural sector first declines with the share of urban workers, and then, beyond the level of urbanization $\hat{l}_{U}$, it rises (Equation (6)). The minimum of the curve $\Pi_{a}$ identifies, by definition, the critical threshold for urbanization, $\hat{l}_{U}=1-\hat{l}$.

\footnotetext{
${ }^{21}$ The literature has emphasized that in large cities, the long-term average of deaths was significantly higher than that of births. Only a permanent stream of rural immigrants made it possible for these cities to maintain their populations in the long run: urban centers acted as a drain on the human resources of the countryside, depleting its younger manpower (Helleiner, 1967).
} 


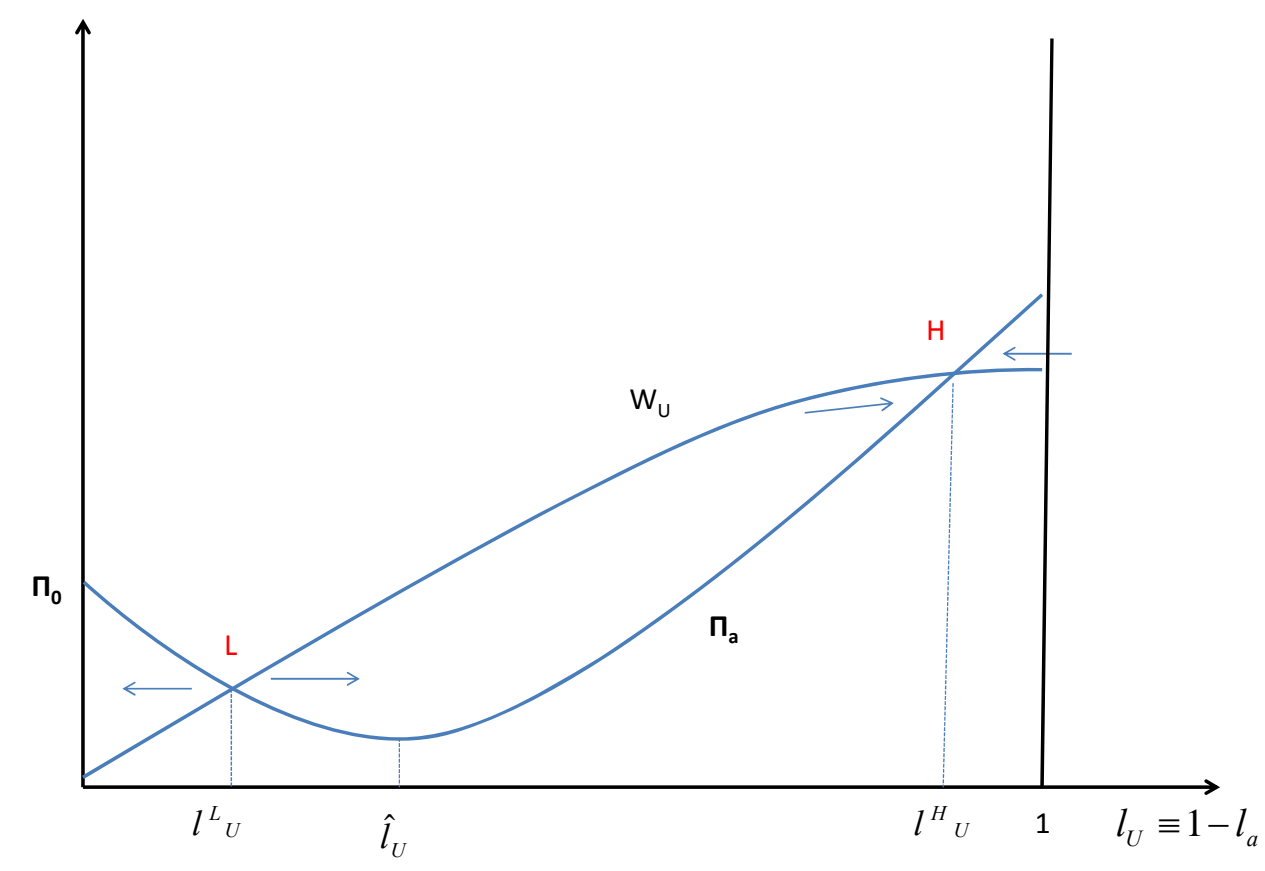

Figure 9 shows two equilibria with urbanization $(L$ and $H)$ and one primitive equilibrium $\left(\Pi_{0}\right)$. The latter represents a corner solution characterized by a primitive economy: a pre-market epoch prior to the establishment of cities. Here we focus on the urban equilibria.

The first (and lowest) equilibrium is characterized by low emigration from the rural to urban sector, $l_{U}^{L}$, whereas the upper equilibrium is results from a high proportion of labor in the urban sector, $l^{H}$. In the low urbanization equilibrium (intersection between curves is in $L$ ), the level of urbanization is smaller than the lower critical threshold, $\hat{l}_{U}$ (the share of rural workers is larger than the threshold generating increasing returns to labor, i.e. $l_{a}^{L}>\hat{l}$ ). Conversely, in the high urbanization equilibrium (intersection in point $H$ ) the urban population lies above the threshold.

There are two conditions for the stability of an equilibrium, or the stability of migrant flow/urbanization: equality between remuneration in the two sectors (the intersection) and the absence of incentives to move from one sector to another (the gap between the two curves). In the low urbanization equilibrium the second condition is not fulfilled, as workers, given the 
productivity gap, have the incentive to move either to the upper equilibrium or to go back to the countryside. Conversely, the high urbanization equilibrium is a stable one: given the flow of migration from the countryside to the city, it is no longer worthwhile for workers to migrate from the rural to the urban sector where they would get a lower wage. ${ }^{22}$

This scheme of demographic migration from the rural to the urban sector is useful for analyzing the role of urbanization in economic transition. The evidence available for pre-industrial Italy can be consistent with an urbanization level which is to the left of minimum rural productivity, since during the expansion of cities (see Figure 4) Italy experienced a decline in rural wages. Starting from 1430 there is a continuous decline in wage rates, which also includes the period of rapid urbanization in the early 16th century. This situation can be represented by the $L$ equilibrium: rural marginal productivity is negatively sloped (we are in the convex side of rural technology as a function of $l_{a}$ ). However, as we have remarked, the $L$ equilibrium is unstable, and a powerful and positive shock in population could drive the economy toward the $H$ equilibrium. Graphically (see the dashed curves in Figure 10), the response of rural productivity to an increase in population is a downward rotation of the marginal productivity curve. Moreover, we also observe an increase in the threshold of rural labor; hence the minimum rural productivity moves leftward, from $\hat{l}_{U}$ to $\hat{l}_{U}^{*} \cdot{ }^{23}$ In the meanwhile, a positive shock to population makes market production more profitable, with the wage rotating upward around the left hand origin.

\footnotetext{
22 The simplistic assumption of production of a homogeneous good can be easily eliminated without affecting substantially the interpretative scheme presented above. Precisely, preferences should be of the Stone - Geary type: $U\left(c_{a}, c_{u}\right)=\alpha \log \left(c_{a}-\overline{\bar{c}}\right)+(1-\alpha) \log c_{u}$ where $c_{u}$ and $c_{a}$ stand for consumption of urban and rural goods, respectively, and $\overline{\bar{c}}$ is the subsistence level of rural good consumption. Hence, for a given technology, and for a given level of population, we have an additional constraint, namely that food production must be such that basic needs are fulfilled:

$$
Y_{A G R}=f\left(l_{a}\right) \geq \overline{\bar{c}} L_{T O T}
$$

In terms of our analysis, this requires that there is a second threshold for the share of rural workers (size of urban migration). Let it be denoted by $\overline{\bar{l}}_{a}$, to which corresponds $\overline{\bar{l}}_{U}=1-\overline{\bar{l}}_{a}$. As long as $\overline{\bar{l}}_{a}<\hat{l}_{a}$, the comment described above still works, with the only change that $\overline{\bar{l}}_{U}$ would now identify a maximum of urbanization, which can be lower than the high urbanization equilibrium.

${ }^{23}$ We are assuming that the increase in workforce reduces the area of increasing marginal productivity in agriculture, i.e. the area of convex technology shrinks, therefore the threshold of rural workforce, $\hat{l}_{a}$, increases. By consequence, in Figure 9 the critical threshold of urbanization, $\hat{l}_{u}$, shifts leftward $\left(\hat{l}_{u} \equiv 1-\hat{l}_{a}\right)$.
} 
Figure 10:the pre-industrial economy with urbanization and convex rural technology, the effect of population shocks

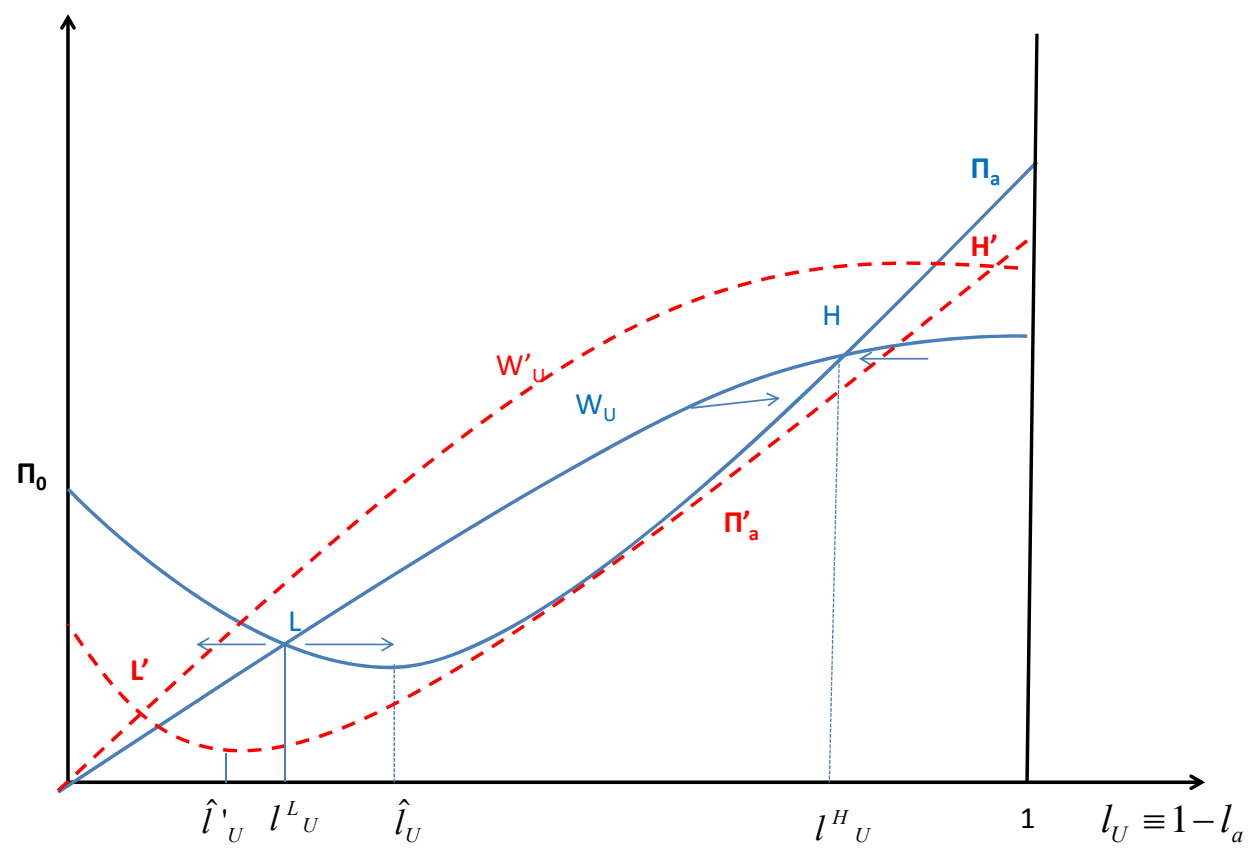

After the shock, the new equilibria are in points $L^{\prime}$ and $H^{\prime}$, the new intersections of the dashed curves. Interestingly, with regard to the post-shock equilibrium, $L^{\prime}$, the pre-shock urbanization rate $l_{U}^{L}$ lies on the positively sloped arm of the new rural productivity. Thus, a positive shock to population is the mechanism able to trigger a transition toward the high urbanization equilibrium. Conversely, the appearance of disease, warfare and famine, which for about 400 years of our sample had been the main "agents" of demographic dynamics in Italy, were the real engine of this economy. The negative shocks on population, making cities into death-traps, raised wages in the rural sector, shifting the $\Pi_{a}$ curve upward and the $W_{U}$ curve downward. These negative shocks curbed the process of migration to towns, often generating an inverse process (see Figure 8), both for the better hygiene conditions and higher wages. ${ }^{24}$ In our graphical analysis of Figure 9, by inverting the pre- and post-shock curves, this process is represented by the larger gap between rural and urban productivity. Note that a negative shock to population has an economic effect similar to

\footnotetext{
${ }^{24}$ See, amongst others, Voigtlander and Voth 2013 and the discussion in Alfani and Percoco 2014 who investigate the interaction between two waves of Plague, 1575-77 and 1629-30, that caused a productivity shock, worsening the trajectory of development of Italian cities.
} 
that derived from technological progress, with higher labor productivity in the countryside, which contributes to emptying the city.

Thus the urbanization process does not appear to have been sustainable or able to trigger the economic transition to a market-based economy since the share of rural labor, $l_{a}$, was too high (Italy was in a neighborhood of a low and unstable urbanization equilibrium) and the population, due to the epidemics that had ravaged Italy, did not grow sufficiently to support the flow of urban dwellers (see again Figure 8). The first stage of urbanization occurred when the population was too small to support a market sector. When the veritable growth in population occurred, namely in the late 18th century, the urbanization process had already slowed down. In the next section, with the data at our disposal on the rural wage, population and urbanization, we provide empirical support for the above framework.

\section{Vector error correction analysis: simulation results}

In this section we ascertain whether the data support the intuition of a negative relationship between rural productivity and urbanization and verify the effects of a positive population shock. To this aim, we estimate a VAR-cointegrated model in three endogenous variables: population, urbanization and rural wage.

We use Johansen's (1995) technique to estimate and test the time series models. Estimation is carried out over the period 1320-1870 using a two-stage procedure (See Lutkepohl and Kratzig, 2004). This procedure is a tool for checking the validity of the weak exogeneity hypothesis and to investigate the strength of feedback coefficients to disequilibrium. Estimates, tests and robustness analysis are reported in Appendix II.

\subsection{Simulation results}

The following plots show the reaction of each variable to the one standard innovation shock of each other. The dynamic responses of population, rural wages and urbanization rate are depicted, 
respectively, in Figures 11, 12 and 13. We plot the impulse responses (IR) together with bootstrapped confidence intervals. ${ }^{25}$

Figure 11: response of population to rural wages (left) and urbanization (right); VECM orthogonal IR
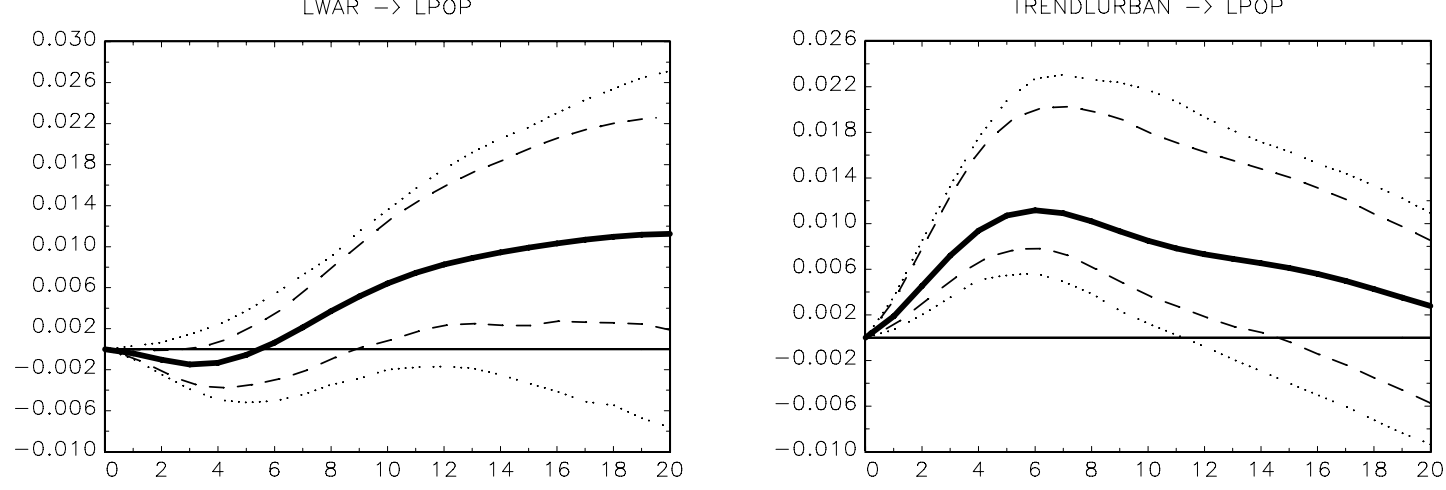

The solid line represents the estimated response; the dashed (dotted) line is the $90 \%$ (95\%) Hall percentile confidence interval.

The estimated IR shows that against the Malthusian scheme, in Italy before industrialization the income-population feedback is reversed, at least in the first five decades. ${ }^{26}$ As shown by Figure 11 , there is significant evidence for the population's positive response to rural wages (the main source of income) only a century after the original impulse.

Conversely, a rise in the urbanization rate provides an increase in population, but the effect is not long-lasting. Unlike the model of Sato and Yamamoto (2005), in which urbanization reduces fertility rates and hence population growth, helping to explain the inverted U-shaped demographic transition, in pre-modern Italy we estimate a $1 \%$ rise in population growth after a positive shock to urbanization. This implies that, during the examined period, the urbanization process and the agglomeration and congestion externalities at work in towns were not strong enough to trigger the demographic transition. This is hardly surprising given that, as emphasized by Alfani (2013b), during the centuries in question Italy was still experiencing an upper ceiling to its demographic growth, and urbanization experienced a declining trend. On the other hand, overpopulated urban

\footnotetext{
${ }^{25}$ We use the Hall (1992) method to obtain the confidence intervals, based on 1000 bootstrap replications.

${ }^{26}$ Chiarini (2010) stresses that the Malthusian relationship between income and population growth did break down in the pre-industrial Italian epoch.
} 
centers were periodically struck by epidemics, social disorder and invasions, ${ }^{27}$ reducing population levels not only in cities but also in rural areas, and increasing real wages in the agricultural sector (a detailed analysis of the impact of plague in the peninsula rural areas is in Alfani, 2013a).

Figure 12: response of rural wage to population (left) and urbanization (right). VECM orthogonal IR
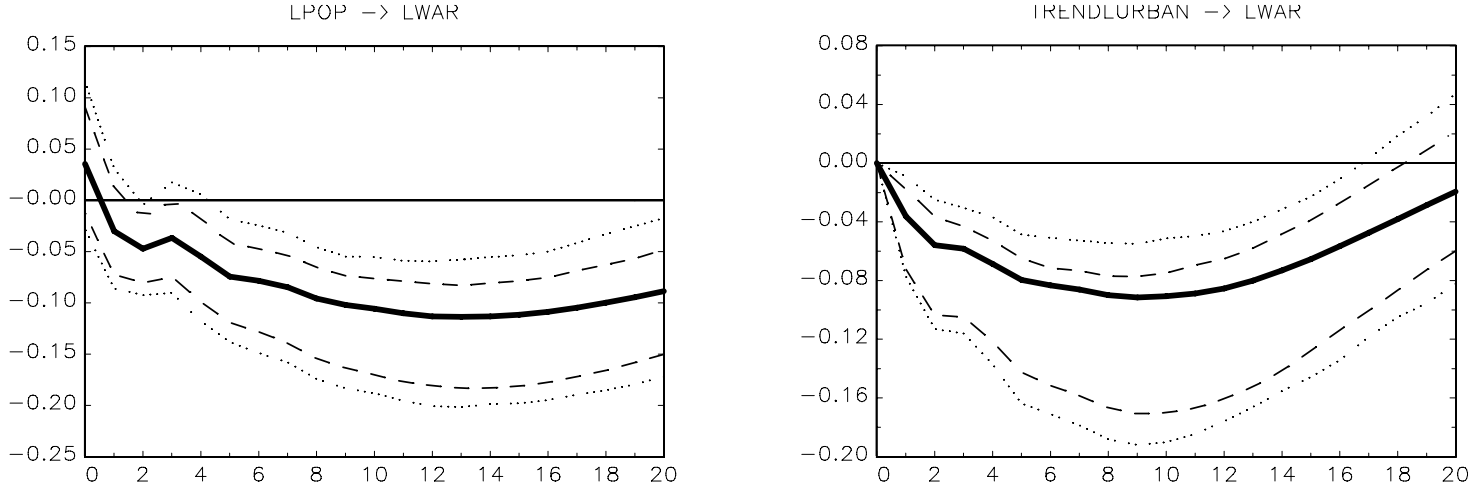

The solid line represents the estimated response; the dashed (dotted) line is the 90\% (95\%) Hall percentile confidence interval

As to the dynamic of rural wages, our estimates show that both positive changes in population and urbanization entail a drop in rural real wages (Figure 12). The former effect is consistent with technology characterized by decreasing returns to scale for the labor input, such that the increase in the rural workforce would mean a decrease in productivity and wages. This result suggests that during the examined sample, the effect of Boserupian mechanisms did not offset the negative effect of population on rural wages and this is consistent with the evidence provided in Section 4 (see Moller and Sharp, 2014, for different evidence for England).

The latter effect could at first glance seem counter-intuitive. Given that an increase in the share of urban inhabitants is tantamount to a reduction in the rural workforce, this workforce migration should produce higher labor productivity and wages in the rural sector. However, the crucial point here is that population and urbanization act as different shocks to rural productivity, given the

\footnotetext{
${ }^{27}$ Of the most important destructive events occurring in the $16^{\text {th }}$ century, we should mention the French sack of Brescia (1511) and Pavia (1528); in 1527 Rome was sacked by the mutinous troops of the Emperor Charles V, and Spanish troops sacked Genoa in 1532.
} 
mechanisms highlighted in Section 5. The exogenous shock to urbanization, in a neighborhood of a low urbanization equilibrium, operate a selective process of reduction in rural population.

In the economy outlined above, the workforce that migrates from the countryside to the town is younger, physically stronger and more open to learning. Migration of such workers necessarily impoverishes the workforce remaining in the countryside, reducing (already low) total factor productivity and causing a decline in rural wages.

Figure 13: response of urbanization to population (left) and rural wages (right). VECM orthogonal IR
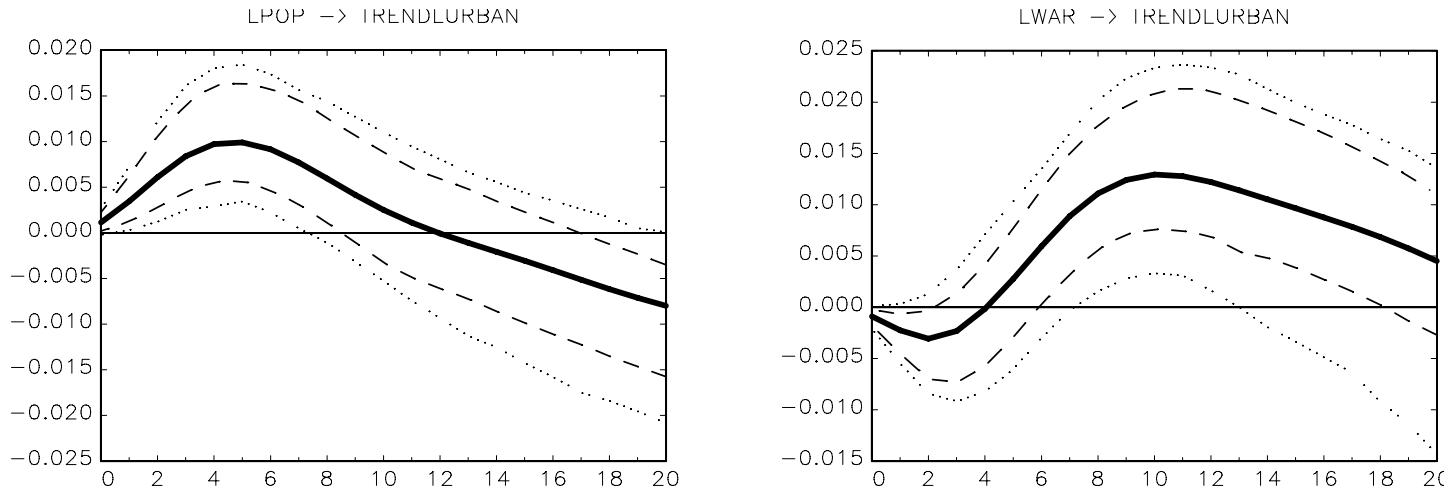

The solid line represents the estimated response; the dashed (dotted) line is the $90 \%$ (95\%) Hall percentile confidence interval.

Turning to our main variable of interest, the urbanization rate rises after an increase in population size (Figure 13, left-hand panel). This is in line with the comparative static exercise illustrated in the previous section (Figure 10). A further interesting characteristic concerns the dynamic path of urbanization: after a change in the population the urbanization rate slowly converges to the previous equilibrium after about 40-50 years and then declines. Hence, a positive trend in population dynamics does not necessarily trigger an endurable process of urbanization, while it is consistent with a stop-and-go dynamic and confirms that cities and towns, under the many adverse shocks, tend to inflate and deflate, creating continuous migration flows.

Interestingly, in the "short run" there is an inverse relationship between rural real wages and the urbanization process: increases in agricultural wages curb people's willingness to leave the countryside and agricultural sectors for towns and new crafts and jobs. They also produce an 
inevitable future increase of population in the cities, since increased rural productivity allows sustenance of urban areas. Actually, in the long term, higher rural wages influence the rate of urbanization positively (Figure 13, right-hand panel). This empirical evidence can be connected with the framework depicted in Section 5 (Figures 9 and 10). Starting from a largely rural economy (the low equilibrium), and considering a homogeneous good, the productivity shock is tantamount to an upward translation of both the $\Pi_{a}$ and $W_{U}$ curve, with a new low equilibrium characterized by higher productivity. As to urbanization, in the new equilibrium it can rise or decline depending upon the two technologies. In any case, even in this latter situation (the new equilibrium lies to the left of the previous one) the stability properties described in Figure 9 would drive urbanization upward.

\section{Concluding remarks}

Our analysis was framed in the wake of a continuing debate about the failed transition of Italy to sustained growth during the 16th century. Starting from some descriptive evidence available for the period 1320-1870, we proposed a conceptual framework to tackle this intriguing issue. Our main contribution, validated by the estimated VAR model, suggests that in an early stage of development, migration to cities may have had negative consequences for rural marginal productivity. The crucial point here is to disentangle the effects on rural productivity originating from a population shock or an urbanization shock. We stress that the effects are radically different, because only the latter brings about a selective reduction in population, impoverishing the quality of the workforce in the countryside, bringing down labor productivity.

The first factor emerging from our analysis is the prime role played by population, the main stochastic force that governed the socio-economic performance of Italian society in the observed time-span, which affected urbanization and the economic structure. Our estimates show that it did not play a positive role for economic transition. Impulse responses show that over the period from the $14^{\text {th }}$ to the $19^{\text {th }}$ century, increases in population size were absorbed by a deterioration in the rural 
real wage. This evidence is consistent with univariate analysis showing that the force driving per capita productivity, the population growth rate, is a stationary variable. As a consequence, it is unable to shift the technological frontier permanently onto a higher equilibrium.

The second result concerns the interaction between urbanization and rural wages, that seems to confirm that the Italian economy was trapped in a low urbanization equilibrium. Although this equilibrium is unstable, the economy was unable to shift to the upper equilibrium because the population was too low. Indeed, during the pre-industrial era in Italy there were several abrupt breaks in the demographic trend, which were non-neutral for aggregate economic performance: the stop-and-go process of urbanization, affected by demographic as well as economic variables, prevented the triggering of an economic transition toward a more efficient economic structure.

Overall, the Italian economy during the period 1320-1870 appears to display "primitive” aspects which do not allow an infant technology in the primary sector to shift human resources into urban production to raise economic efficiency along with a continuous increase in output per worker. 


\section{Appendix I}

\section{Trend characteristics}

In this section we investigate the main characteristics of our variables of interest: population, urbanization rate, wages, and share of agriculture in total GDP. The order of integration of macroeconomic variables has crucial consequences for appropriate modeling of time series data and for proper understanding of the aggregate phenomenon. It is widely acknowledged that the form of non-stationarity in a time series may well not be evident from examination of the series. Moreover, deterministic rather than stochastic trends have major economic implications. A trend-stationary time series evolves around a deterministic trend, i.e. around some specified and predictable function of time. Conversely, a series with a stochastic trend has no clear long-run pattern, since its longterm movement is affected by stochastic disturbances, which have an enduring effect on the future path of the series. In our context, this means that a shock occurring to the estimated series of population and real wages due, for instance, to weather, harvest, epidemics etc., may have a permanent impact on the long-run movement of the series.

A stochastic trend may give rise to spurious regressions; they provide, if erroneously identified, uninterpretable or misleading results. Therefore, as a first step, we run the unit root test, reported in Tables A1, A2 and A3.

The augmented Dickey-Fuller (ADF) test (Table A1) examines the null hypothesis of a unit root whereas the KPSS test (Table A2) examines the null hypothesis of trend/level stationarity (Kwiatkowski et al., 1992). We use the appropriate test statistics tabulated by Dickey and Fuller (1981) to test joint hypotheses on the deterministic coefficients (trend and drift). ${ }^{28}$ The lags included in the ADF test are consistent with the lag order selection criteria and with the evidence provided by

\footnotetext{
${ }^{28}$ One of the critical issues in using the ADF tests to investigate the presence of unit root is whether an intercept and /or time trend has to be included in the regression equation. The power of the DF test is negatively affected by misspecification concerning the deterministic part of the regression. When the form of the data generating process is unknown, Enders (1995) suggests as an appropriate strategy starting from the less restricted specification, i.e. with a trend and a drift, and, in the case of non-rejection of the unit root hypothesis, to proceed to determine whether too many deterministic terms are included. This may be done by using the appropriate test statistics tabulated by Dickey and Fuller (1981) to test joint hypotheses on the coefficients.
} 
the Partial Autocorrelation Function (PACF), whereas in the KPSS test we considered three and ten lags

Table A 1: Augmented Dickey Fuller Test for unit root. Null Hypothesis: unit root

\begin{tabular}{|l|l|l|l|l|}
\hline & \multicolumn{2}{|c|}{ Level } & \multicolumn{2}{c|}{ First Difference } \\
\hline & Test statistic & Deterministic (lags) & Test statistic & Deterministic \\
& & & & \\
\hline (lags)
\end{tabular}

When the evidence about the deterministic components and/or the lags to be included in the ADF test is not clear-cut, we compare the test statistics for the most plausible specifications. The information criteria suggest two lags be included in the ADF test for the population, whereas the PACF would suggest employing only one lag; on the other hand, when considering real wages, test statistics tabulated by Dickey and Fuller (1981) would recommend to specify, as the null hypothesis, a pure random walk model, whereas graphical inspection of the variables clearly shows that the wage variables display a declining trend. These decisions are not neutral as to the statistical properties of the variables involved. For instance, on using two lags, the population variable proves to be a stationary process, with a significance of $1 \%$, whereas the pi-value rises to $10 \%$ when using only one lag. On the other hand, the choice of the deterministic trend is crucial for the wage variable. 
Table A 2: KPSS Test for unit root. Null Hypothesis: no unit root

\begin{tabular}{|l|l|l|l|l|}
\hline & \multicolumn{2}{|c|}{ Level } & \multicolumn{2}{c|}{ First Difference } \\
\hline & lags & & $\begin{array}{l}\text { Test statistic: } 2 \\
(9) \text { lags }\end{array}$ & Null hypothesis \\
\hline Population (log) & $0.17^{* *}\left(0.13^{*}\right)$ & Trend stationarity & $0.46^{*}\left(0.36^{*}\right)$ & Level stationarity \\
\hline Urbanization (log) & $0.46^{* *}(0.28)$ & Level stationarity & $0.10(0.09)$ & Level stationarity \\
\hline Rural (real) wage index & $0.12^{*}(0.07)$ & Trend stationarity & $0.068(0.07)$ & Level stationarity \\
\hline Share of agriculture in total GDP & $0.21(0.13)$ & Level stationarity & & \\
\hline \\
Thresholds (constant and trend): $1 \%(0.216) \quad 5 \%(0.146)$ & $10 \%(0.119)$ & \\
Thresholds (constant): & $1 \%(0.739)$ & $5 \%(0.463)$ & $10 \%(0.347)$ & \\
\hline
\end{tabular}

In addition, the response of different tests may be the opposite. For instance, as to the variable population, while the ADF test would reject the null hypothesis of a random walk, the KPSS rejects the null of trend stationarity. Conversely, for the ratio of agriculture to total GDP, the ADF test does not reject the null of stochastic trend, whereas the KPSS statistic does not reject the null of stationarity. The previous results assume that there is no structural break in the series, whereas the historical analysis reported above depicts a population dynamics with peaks and notable changes in trend, especially in the first part of the sample when the Black Death appeared (1348-49). Similarly, the slope of the agriculture-to-total GDP seems to change in the early 16 th century.

Therefore, we test the hypothesis of unit root for population (log transformed), allowing for a structural break (endogenously found). As to the population, two alternative breaks are found, in the late 14th and 17th centuries, whereas for the share of agriculture in GDP a single break is found in 1520; for all the specifications, the null hypothesis of unit root cannot be rejected, as shown in Table A3, for both variables. Here we refer to the unit root test proposed by Lanne et al. (2002). 
Table A 3: Unit root test with structural break (Lanne et al., 2002). Null Hypothesis: unit root

\begin{tabular}{|l|l|l|l|l|}
\hline & Test statistic & Deterministic (lags) & $\begin{array}{l}\text { Break } \\
\text { Date }\end{array}$ & Type of break \\
\hline Population (log) & -2.18 & intercept, time trend, (1) & 1360 & Exponential shift \\
\hline Population (log) & -1.33 & intercept, time trend, (2) & 1640 & Rational shift \\
\hline $\begin{array}{l}\text { Share of agriculture in } \\
\text { total GDP }\end{array}$ & $-2.88^{*}$ & intercept, time trend, (1) & 1520 & Level shift \\
\hline
\end{tabular}

\section{The Model}

The estimated model commented upon in Section 6 is derived from a three-variable system with two cointegrating equations and a lag structure $p=2$. Consider the following VAR (ECM error correction) model, written in the usual notation (Johansen (1995):

$$
\Delta y_{t}=\Pi y_{t-1}+\sum_{i=1}^{p-1} \Gamma \Delta y_{t-i}+B z_{t}+\varepsilon_{t}
$$

where

$$
\Pi=\sum_{i=1}^{p} A_{i}-I ; \quad \Gamma_{i}=-\sum_{j=i+1}^{p} A_{j}
$$

In our case, $\mathrm{y}$ is a $k$-vector and contains three non-stationary variables (population, wages and urbanization rate), $z$ is a vector of deterministic variables and $\varepsilon_{t}$ is a vector of innovation. $A_{i}$ and $B$ 
are matrices of coefficients to be estimated. It is well known that if the coefficient of the matrix $\Pi$ has a reduced rank ( $r<k=2$ the number of cointegrating relations in our case), there exist $3 \times 1$ matrices $\alpha$ and $\beta$ such that $\Pi=\alpha \beta$ ' where $\beta$ is a cointegrating vector and $\alpha$ are the adjustment parameters.

We have seen that our series are characterized, other than by stochastic trends, by non-zero means and deterministic trends. In a similar way, the stationary relations may call for intercepts and trends. We cannot rule out the following assumption (the level data have linear trends; the cointegrating equations have only a drift):

$$
H(r): \Pi y_{t-1}+B z_{t}=\alpha\left(\beta^{\prime} y_{t-1}+\mu_{0}\right)+\alpha \perp\left(\gamma_{0}\right)
$$

In the following tables we report the main diagnostic test for the estimated VEC model.

Table A 4: residual autocorrelation tests for the VEC Model

\begin{tabular}{|lllll|lc|}
\hline Test & ARCH_LM & ARCH_LM & ARCH_LM 16 & LM $_{16}$ & LM $_{5}$ & Multiv. \\
& $\left(\mathrm{u}_{1}\right)$ & $\left(\mathrm{u}_{2}\right)$ & $\left(\mathrm{u}_{3}\right)$ & & & ARCH_LM $_{5}$ \\
\hline Test statistic & 17.93 & 19.55 & 9.51 & 9.12 & 49.97 & 156.15 \\
p-value & 0.33 & 0.24 & 0.89 & 0.43 & 0.28 & 0.90 \\
\hline
\end{tabular}

Table A 5: residual non-normality tests for the VEC Model

\begin{tabular}{|c|c|c|c|c|c|c|}
\hline \multirow[t]{2}{*}{ Test } & \multicolumn{3}{|c|}{ Doornik Hansen (1994) } & \multicolumn{3}{|c|}{ Lutkepohl (1993) } \\
\hline & joint & skewness & kurtosis & joint & skewness & kurtosis \\
\hline Test statistic & 9.17 & 6.05 & 3.12 & 10.29 & 6.84 & 3.45 \\
\hline p-value & 0.16 & 0.11 & 0.37 & 0.11 & 0.08 & 0.33 \\
\hline
\end{tabular}


Table A5: residual non-normality tests for the VEC Model (continued)

\begin{tabular}{|lccc}
\hline Test & \multicolumn{3}{c}{ Jarque Bera } \\
\hline & $\mathrm{u}_{1}$ & $\mathrm{u}_{2}$ & $\mathrm{u}_{3}$ \\
\hline Test statistic & 0.90 & 1.19 & 1.32 \\
p-value & 0.63 & 0.55 & 0.52 \\
\hline
\end{tabular}




\section{APPENDIX II}

\section{-Cointegrating space:}

The cointegrating space contains an intercept; Trace and Maximum Eigenvalue tests indicate that it is characterized by two stationary relations at the 0.05 level.

Using decadal data for 1320-1870, the analysis supports the choice of one common stochastic trend and two stationary relations. The space within which the cointegrated variables move (the attractor set) is a hyperplane with a dimension determined by the three endogenous variables and two cointegrating relationships:

$$
\begin{aligned}
& \beta_{1}^{\prime} y: \quad \text { pop }+\underset{(5.69)}{6.59} \text { Urban }-\underset{(-8.23)}{27.38} \\
& \beta_{2}^{\prime} y \quad w a-\underset{(-4.48)}{13.70 U \text { Uban }}+\underset{(4.17)}{36.64}
\end{aligned}
$$

In (1), t-values are given in parentheses underneath the coefficient estimates. The cointegrating vectors are overidentified as two restrictions are imposed on each of them.

We recall that the cointegration vectors cannot be interpreted as representing structural equations because they are obtained from the reduced form of a system where all of the variables are jointly endogenous. Thus, although these relations taken alone as well as each single equation taken alone may seem economically significant structures, they are only indicative.

\section{-Adjustment coefficients:}

Using a two-stage procedure in which the beta vectors are estimated first and then fixed in the second stage, we may treat alphas in the same way as the short-run parameters. The strategy chosen is a sequential elimination of the short-run parameters and loading factors, based on model selection 
criteria (Akaike Information Criterion). The search for zero-restrictions on loading factors provides the following set of coefficients:

$$
\begin{aligned}
& \alpha_{p o p 1}=\underset{(1.94)}{0.011} \quad \alpha_{p o p 2}=0 ; \\
& \alpha_{w 1}=\underset{(-3.54)}{-0.47} \quad \alpha_{w 2}=\underset{(-1.98)}{0.103 ;} \\
& \alpha_{u r b 1}=\underset{(2.37)}{0.008} \quad \alpha_{u r b 2}=\underset{(3.87)}{0.005}
\end{aligned}
$$

The $\alpha$ coefficients relate the error correction terms $\beta_{1}, \beta_{2}$ (the long run) with the first differences (the short run) of the endogenous variables pop, $w a$ and $u r b$. Thus, $\alpha_{p o p 1}$ measures the intensity of adjustment to the first long-run relation (error correction) in the population equation; $\alpha_{p o p 2}$ is the second error correction described above $\left(\beta_{2}\right)$ in the population equation and so on. The loading factor estimates emphasize that population and urbanization rate adjustments are rather sluggish whereas wage adjustments to deviations from disequilibria are more rapid.

\section{-Exogenous and deterministic variables}

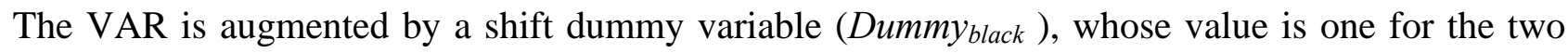
decades after the Black Death (1348-49), when the largest reductions in population were recorded (31.8 and $-21.8 \%$ respectively in the first and second decade after 1350). As for urbanization, it was deeply affected by the Black Death, with a sudden and persistent decline in the 1340s, when the urbanization rate declined from 21.4 to $17.7 \%$. Therefore we add an impulse dummy accounting for the 1350 observation. ${ }^{29}$ Three further dummies are included in the model to account for outliers in the population series: 1640 , to account for the effects of the plague of $1629-30 ; 1420$, when the

\footnotetext{
${ }^{29}$ Impulse dummies describe a permanent intervention/shock, whereas shift dummies are recommended when there is a temporary "regime change”. Since we use dummies in the VEC model, where all variables are expressed in first differences, it is useful to recall that: a temporary break in the trend component of a variable becomes a level shift in the differenced variable, whereas a shift in the levels of a variable becomes an impulse dummy in the differenced variable.
} 
population growth rate was $-10 \%$, and 1850 , with a positive growth in population amounting to 18.6\%. An exogenous variable (Temper) is included in the VAR to allow for the temperature effects on the endogenous variables. ${ }^{30}$ Below we report the coefficients and the t-values which are statistically significant for the respective equations:

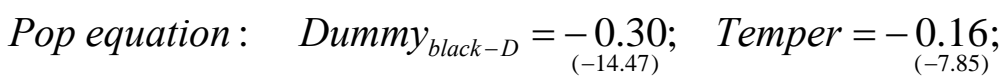

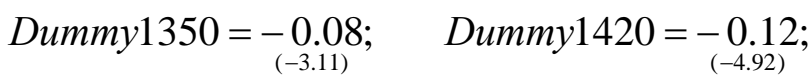

$$
\begin{aligned}
& \text { Dummy1640 }=\underset{(-8.92)}{-0.23 ; \quad \text { Dummy1850 }}=\underset{(6.24)}{0.16} \text {. }
\end{aligned}
$$

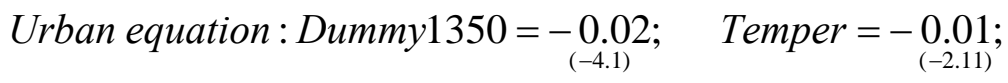

$$
\begin{aligned}
& \text { Dummy } 1640=\underset{(-2.34)}{-0.01}
\end{aligned}
$$

As expected, plagues have a negative effect on demographic variables. When examining the Black Death, we see that it has caused a temporary change in slope in the population level (the Dummy black is significant), whereas it is a veritable structural break for urbanization which, as expected, immediately declines and stays on a lower level for quite a long period (the Dummyblack is not significant while the Dummy1350 is). The short-run effect of the temperature change is negative both for population and, to a lesser extent, for urbanization. ${ }^{31}$

As for the innovation correlation matrix, reported in Table A 6, there emerges some residual correlation between population and the urbanization trend. In the presence of a significant residual correlation, it is advisable to check the robustness of Impulse Response analysis to the ordering of the correlated variables. In our case, however, we deem that the demographic process characterizing the population dynamic can be considered a “deep” parameter that justifies the ordering of urbanization (and wages) after the variable population and not vice versa.

\footnotetext{
${ }^{30}$ The data set is taken from Crowley (2000), which reports the phases in the temperature of the Northern Hemisphere. However, the inclusion of these data may be a valid approximation. A detailed analysis of climate change for different epochs and their possible effects on the economy may be found in Malanima (2002).

${ }^{31}$ It is not clear how fluctuations in temperature may affect the economy. For instance, in Mediterranean regions, an increase in temperature may give rise to drought and therefore negatively impact on harvests and population.
} 
Table A 6: Innovation correlation matrix

\begin{tabular}{|l|l|l|l|}
\hline & Population & Agricultural wage & Urbanization \\
\hline Population & 1.0000 & 0.1650 & 0.2592 \\
\hline Agricultural wage & 0.1650 & 1.0000 & -0.1613 \\
\hline Urbanization & 0.2592 & -0.1613 & 1.0000 \\
\hline
\end{tabular}

- Robustness: inverting the order of wages and urbanization

The simulation results reported in Figure 11-13 are quite robust when the order of the wage and urbanization variables are inverted in the model. In particular, there is still evidence of decreasing returns to scale, since rural wages fall after a positive shock to population. As to the response of wages to urbanization, it is still negative. Both responses are qualitatively similar to those detected in the original model, albeit less significant. Thus, the robustness check confirms that the economic mechanisms at work are not affected by the ordering of the variables. A detailed analysis of robustness is available upon request.

\section{Acknowledgements}

We thank Guido Alfani for his helpful comments. We also thank the participants at the 2012 SIE Conference and the seminar participants at University of Naples Parthenope. We are very grateful to Paolo Malanima for providing the time series used in this paper. 


\section{References}

Acemoglu D., S. Johnson and J.A. Robinson, (2005), The rise of Europe: Atlantic trade, institutional change and economic growth, American Economic Review, 95, 546-579.

Alfani G. and Melegaro A. (2011), Pandemie d'Italia. Dalla Peste Nera all'Influenza Suina, Egea, Milan.

Alfani G. (2013a), Plague in seventeenth-century Europe and the decline of Italy: an epidemiological hypothesis, European Review of Economic History, 17, 408-430.

Alfani G. (2013b), Population dynamics, Malthusian crises and Boserupian innovation in preindustrial societies: the case study of Northern Italy (1450-1800) in the light of Lee's "dynamic synthesis", in Chiarini B and Malanima P (eds.), From Malthus' Stagnation to Sustained Growth, Palgrave-MacMillan, Basingstoke.

Alfani G. and Percoco (2014), Plague and long-term development: the lasting effects of the 162930 epidemic on the Italian cities, IGER Working paper No. 508.

Allen, R. (2001), The great divergence in European wages and prices from the Middle Ages to the First World War, Explorations in Economic History, 38, 411-447.

Allen, R. (2008), A review of Gregory Clark’s A Farewell to Alms: A Brief Economic History of the World, Journal of Economic Literature, 46, 946-973.

Bairoch P. (1981), The main trends in national economic disparities since the Industrial Revolution, in P. Bairoch and L. Maurice (eds.), Disparities in Economic Development since the Industrial revolution, St. Martin’s, New York, NY.

Bairoch, P. (1988), Cities and Economic Development, University of Chicago Press. Chicago.

Bellettini, A. (1973). La Popolazione Italiana dall'inizio dell'Era Volgare ai Nostri Giorni. Valutazioni e tendenze: Storia d'Italia Vol. 5, Einaudi, Torino.

Bencivenga V.R. and Smith B.D. (1997), Unemployment, migration, and growth, Journal of Political Economy, 105, 582-608.

Blockmans, W. (1989), Voracious States and obstructing cities. An aspect of State formation in preindustrial Europe, Theory and Society, 18, 733-755.

Boserup, E. (1965), The Conditions of Agricultural Progress, Aldine Publishing Company, Chicago.

Boserup, E. (1981), Population and Technological Change: A Study of Long-Term Trends. University of Chicago Press, Chicago.

Boucekkine R., de la Croix D., and Licandro O. (2002), Vintage human capital, demographic trends 
and growth, Journal of Economic Theory, 104, 340-375.

Bosker M., Brakman S., Garretsen H., De Jong H. and Schramm M., (2008), Ports, plagues and politics: explaining Italian city growth 1300-1861, European Review of Economic History, 12, 97131

Braudel, F., (1974), Il secondo Rinascimento. Due secoli e tre Italie, Giulio Einaudi Editore, Torino.

Broadberry S. (2013), Accounting for the Great Divergence, University of Warwick, Working Paper, No. 160, September.

Cafagna L. (1989), Dualismo e Sviluppo nella Storia d'Italia, Venezia, Marsilio.

Cervellati M., and Sunde U. (2005), Human capital formation, life expectancy and the process of development, American Economic Review, 95, 1653-1672.

Chiarini B. (2010), Was Malthus right? The relationship between population and real wages in Italian history, 1320 to 1870, Explorations in Economic History, 47, 460-475.

Cervellati M., and Sunde U. (2005), Human capital formation, life expectancy and the process of development, American Economic Review, 95, 1653-1672.

Cipolla C.M. (1969), Literacy and Development in the West, Penguin Books, Ltd., Harmondsworth, Middlesex, UK.

Clark, G. (2006), Interpreting English economic history 1200-1800: Malthusian stasis or early dynamism?, paper presented in XIV International Economic History Congress, Helsinki 2006.

Clark, G., (2007), A Farewell to Alms: A Brief Economic History of the World, Princeton University Press, Princeton.

Cole W.E. and P.D. Sanders (1985), Internal migration and urban employment in the Third World, American Economic Review, 75, 481-94.

Crafts, N., Mills, T.C. (2007), From Malthus to Solow: How did the Malthusian economy really evolve? Mimeo.

Crowley, T. (2000), Causes of climate change over the past 1000 years, Science, 289, 270-277.

De Vries, J. (1984), European Urbanization 1500-1800, Harvard University Press, Cambridge MA.

Del Panta, L., (1980), Le Epidemie nella Storia Demografica Italiana (secoli XIV-XIX), Loescher Editore. Torino.

Doepke M. (2004), Accounting for fertility decline during the transition to growth, Journal of Economic Growth, 9, 347-383.

Doepke M. (2005), Child mortality and fertility decline: Does the Barro-Becker model fit the facts?, Journal of Population Economics, 18, 337-366.

Doepke, M., (2006), Growth takeoffs, New Palgrave Dictionary of Economics, 2nd edition.

Doepke M. and F. Zilibotti (2005), The macroeconomic of child labor regulation, American Economic Review, 95, 1492-1524. 
Eckstein, Z., Schultz, P., Wolpin, K.I. (1986), Short run fluctuations in fertility and mortality in preIndustrial Sweden, European Economic Review, 26, 295-317.

Enders W. (1995), Applied Econometric Time Series, New York: John Wiley \& sons, Inc.

Epstein S.R. (2000), Freedom and Growth: The Rise of States and Markets in Europe, 1300-1750,

London, Routledge.

Galor, O., Weil, D.N. (2000), Population, technology, and growth: from Malthusian stagnation to the demographic transition and beyond, American Economic Review, 90, 806-828.

Galor, O. (2005), Unified growth theory, in Aghion P. and Durlauf S. (eds.), Handbook of

Economic Growth, North-Holland, Elsevier Science. Amsterdam.

Ginatempo M. and Sandri L., (1990), L'Italia delle Città, Le Lettere, Firenze.

Glaeser, E. L. and M. G. Resseger (2009), The complementarity between cities and skills, NBER

Working Paper 15103.

Goodfriend, M., McDermott, J. (1995), Early development, American Economic Review, 85, 116133.

Helleiner K.F. (1967), The population of Europe from the Black Death to the eve of the vital revolution, in Rich, E.E., Wilson, C.H., (eds.), The Economy Expanding Europe in the Sixteenth and Seventeenth centuries. The Cambridge Economic History of Europe, Vol. IV, Cambridge University Press.

Hicks, J.R. (1969), A Theory of Economic History, Oxford University Press, Oxford.

Hohenberg, P.M., Leeds, L.H. (1985), The Making of Urban Europe 1000-1950, Harvard University Press.

Johansen, S. (1995), Likelihood-based Inference in Cointegrated Vector Autoregressive Models, Oxford, Oxford University Press.

Juselius K. (2006), The Cointegrated VAR model, Oxford, Oxford University Press.

Kremer, M. (1993), Population growth and technological change: one million B.C. to 1990, in Quarterly Journal of Economics, 108, 681-716.

Lanne, M., Lutkepohl, H., Saikkonen, P. (2002), Comparison of unit root tests for time series with level shifts, Journal of Time Series Analysis, 23, 667-685.

Lee, R.D. (1997), Population dynamics of humans and other animals, Demography, 24, 443-465.

Lee, R.D., Anderson, M. (2002), Malthus in state space: Macro economic-demographic relations in English history, 1540 to 1870, Journal of Population Economics, 15, 195-220.

Lewis W.A. (1954), Economic development with unlimited supplies of labor, The Manchester School, 22, 139-91.

Lopez R.S. and Miskimin H.A. (1962), The economic depression of the Renaissance, Economic History Review, XIV, 408-426. 
Lutkepohl H. and Kratzing (2004), Applied Time Series Econometrics, Cambridge, Cambridge University Press.

Luzzatto G. (1961), An Economic History of the Italy from the Fall of the Roman Empire to the Beginning of the Sixteenth Century, London and New York.

Malanima, P. (2002), L’Economia Italiana. Dalla Crescita Medievale alla Crescita Contemporanea, Il Mulino: Bologna.

Malanima, P. (2003), Measuring the Italian economy 1300-1861, Rivista di Storia Economica, 19.

Malanima, P. (2005), Urbanisation and the Italian economy during the last millennium, European Review of Economic History, 9, 97-122.

Malanima, P. (2009), Pre-Modern European Economy, Brill, The Netherlands.

Malanima, P. (2013), When did England overtake Italy? Medieval and early modern divergences in prices and wages, European Review of Economic History, 17, 45-70.

McEvedy, C., Jones, R., (1978), Atlas of World Population History, Penguin Books, Harmondsworth.

McNeill W.H. (1977), Plagues and People, New York, Anchor.

Miskimin H. A., Herlihy D. and A. L. Udovitch (eds.) (1977), The Medieval City, New Haven, Yale University Press.

Moller, N. F. and P. Sharp (2014), Malthus in a cointegration space: evidence of a post-Malthusian pre-industrial England, Journal of Economic Growth, 19, 105-140.

Nicolini, E.A. (2006), Was Malthus right? A VAR analysis of economic and demographic interactions in pre-industrial England, Universidad Carlos III de Madrid, Working Paper 06-06.

Pini A.I. (1996), Città Medievali e Demografia Storica, 1996 CLUEB, Bologna

Sato Y. and Yamamoto K. (2005), Population concentration, urbanization, and demographic transition, Journal of Urban Economics, 58, 45-61.

Soares R., (2005), Mortality reductions, educational attainment, and fertility choice, American Economic Review, 95, 580-601.

Storia d'Italia Einaudi, (1974), Dalla Caduta dell'Impero Romano al Secolo XVIII. Einaudi. Torino.

Tilly, C. (1990), Coercion, Capital, and European States, AD 990-1990, Basil Blackwell. Oxford. Todaro, M. P. (1969), A Model of Migration and Urban Unemployment in Less-developed Countries, The American Economic Review 59:138-48.

Todaro, M. P. (1980) Internal Migration in Developing Countries: A Survey, in Population and Economic Change in Developing Countries, ed. Richard A. Easterlin (University of Chicago Press, London and Chicago), pp. 361-402. 
Voigtländer N. and Voth H-J. (2013), The Three Horsemen of Riches: Plague, War, and Urbanization in Early Modern Europe, Review of Economic Studies, 80 (2), pp.774-811.

Weir, D. (1991), A historical perspective on the economic consequences of rapid population growth. in Consequences of Rapid Population Growth in Developing Countries, Taylor \& Francis, London.

Wrigley E.A. (1969), Population and History, McGraw-Hill, New York, NY.

Zhang J. (2002), Urbanization, population transition, and growth, Oxford University Press, 54, 91117.

Ziegler, P. (1969), The Black Death, Collins, London. 